Engineer Research and

Development Center

\title{
Modernization of Deployable Airfield Debris Removal Equipment
}

Ryan C. Strange, Jeb S. Tingle, Donald E. Yule,

and Craig A. Rutland

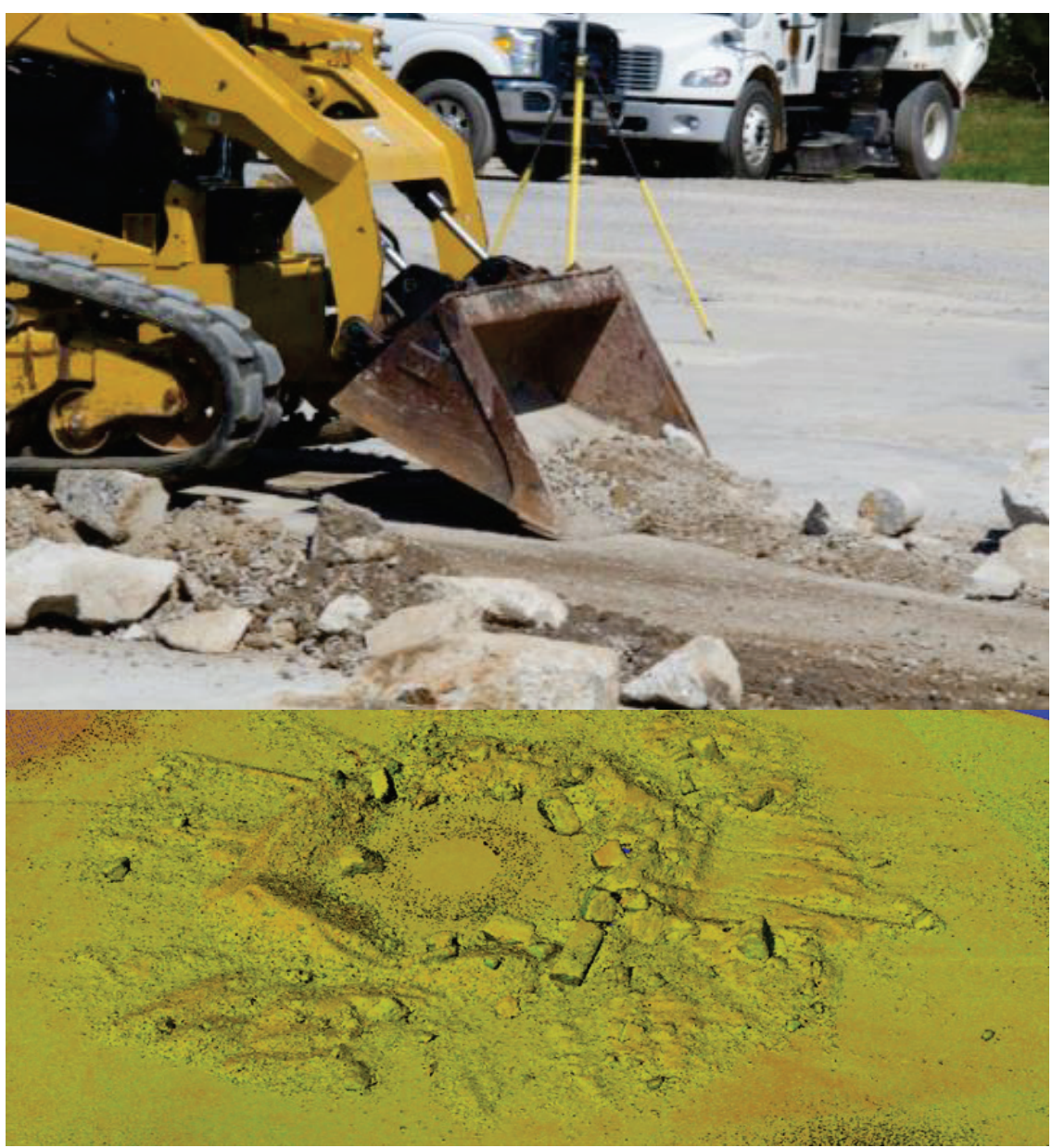


The U.S. Army Engineer Research and Development Center (ERDC) solves the nation's toughest engineering and environmental challenges. ERDC develops innovative solutions in civil and military engineering, geospatial sciences, water resources, and environmental sciences for the Army, the Department of Defense, civilian agencies, and our nation's public good. Find out more at www.erdc.usace.army.mil.

To search for other technical reports published by ERDC, visit the ERDC online library at http://acwc.sdp.sirsi.net/client/default. 


\title{
Modernization of Deployable Airfield Debris Removal Equipment
}

\author{
Ryan C. Strange, Jeb S. Tingle, and Donald E. Yule \\ Geotechnical and Structures Laboratory \\ U.S. Army Engineer Research and Development Center \\ 3909 Halls Ferry Road \\ Vicksburg, MS 39180-6199 \\ Craig A. Rutland \\ Civil Engineering Branch, Engineering Division \\ Air Force Civil Engineering Center \\ 139 Barnes Drive Suite 1 \\ Tyndall Air Force Base, FL 32403-5319
}

Final report

Approved for public release; distribution is unlimited.

\footnotetext{
Prepared for Headquarters, Air Force Civil Engineer Center

Tyndall Air Force Base, FL 32403-5319

Under Work Unit BFK2C4
} 


\section{Abstract}

Research was conducted at the U.S. Army Engineer Research and Development Center to evaluate leaner, lighter equipment for deployable debris removal post missile strikes for airfield damage repair (ADR). LiDAR scans were obtained prior to and after the initial debris removal and were also used in the final debris removal process when using vacuums and sweepers. Photogrammetry was used to obtain measurements and to calculate volumes. A market survey of available loading and sweeping equipment was conducted to populate a database of physical dimensions and time relationships according to identified ADR tasks. Selected equipment was evaluated for maneuverability and efficiency in a realistic environment. Results indicate that mini track loaders with a maximum rated weight of 3,00o lb are capable of performing all identified ADR tasks with an efficiency at or better than the currently utilized 10,000-lb track loaders. Results also indicate that sweeper vacuums with a maximum rated weight of 3,500 lb are capable of performing all identified ADR tasks with an efficiency at or better than the currently utilized 20,000-lb vacuum trucks.

DISCLAIMER: The contents of this report are not to be used for advertising, publication, or promotional purposes. Citation of trade names does not constitute an official endorsement or approval of the use of such commercial products. All product names and trademarks cited are the property of their respective owners. The findings of this report are not to be construed as an official Department of the Army position unless so designated by other authorized documents. 


\section{Contents}

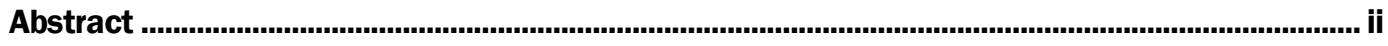

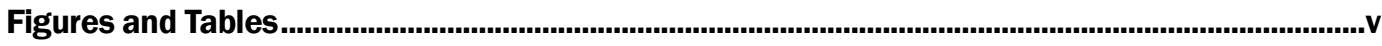

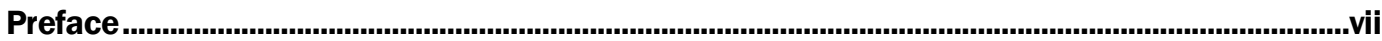

Unit Conversion Factors ..................................................................................................................... vili

1 Introduction .............................................................................................................................. 1

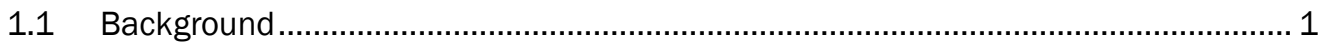

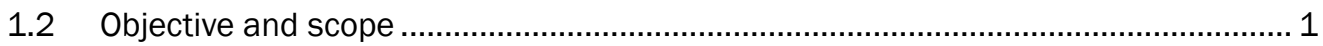

1.3 Current debris removal baseline procedures and equipment ................................ 2

1.4 Crater repair tasks........................................................................................... 2

1.5 USAF problems with existing baseline equipment and minimum requirements for next generation debris equipment ................................................. 3

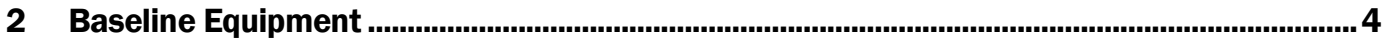

3 Market Research for Potential Next Generation Equipment .............................................. 6

4 Equipment Evaluation Test Procedures.................................................................................10

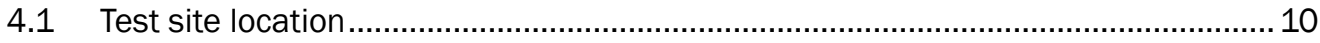

4.2 Initial debris removal evaluation...................................................................... 11

4.3 Final debris removal evaluation........................................................................... 12

4.4 Test methods for quantification of equipment performance ...............................13

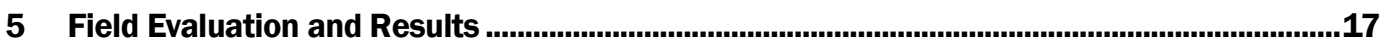

5.1 Field evaluation ........................................................................................ 17

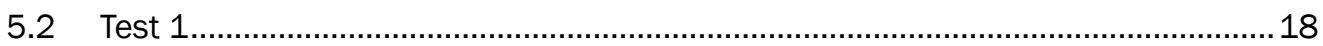

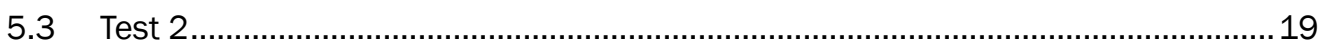

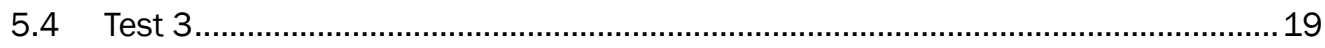

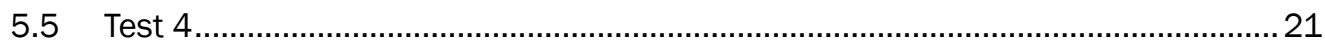

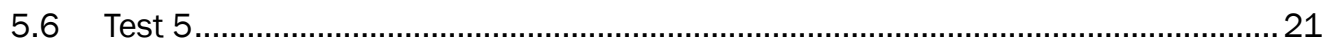

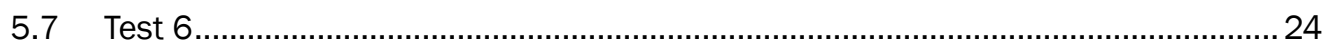

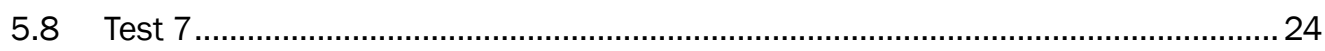

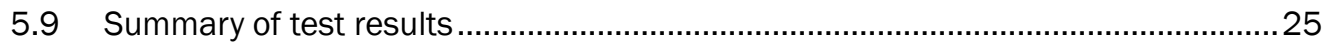

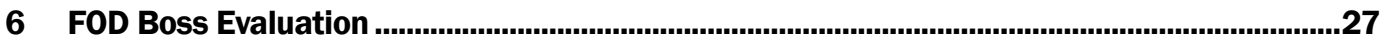

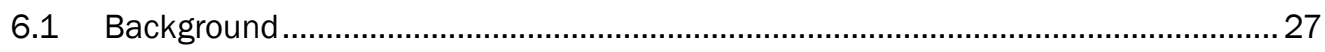

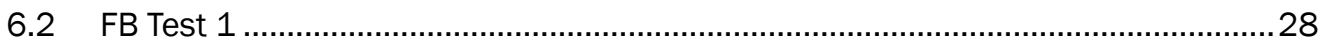

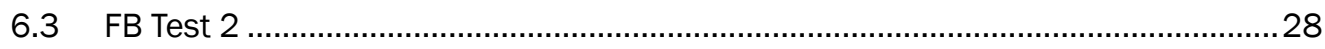

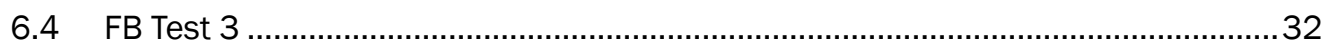

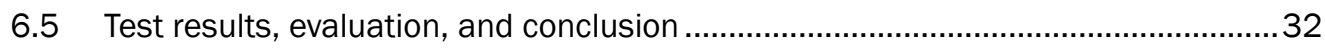




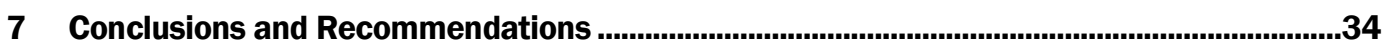

7.1 Market surveys of potential of next generation equipment mini track

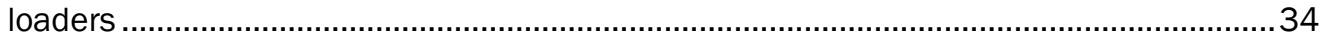

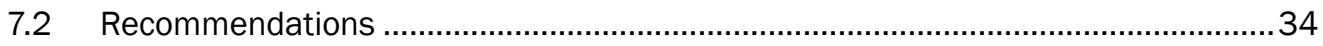

References ….........................................................................................................................................36

Report Documentation Page 


\section{Figures and Tables}

\section{Figures}

Figure 1. KOMATSU WA 150 loader. ................................................................................................

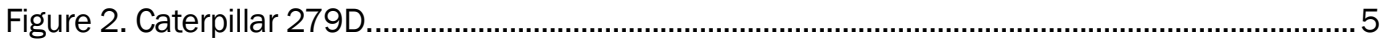

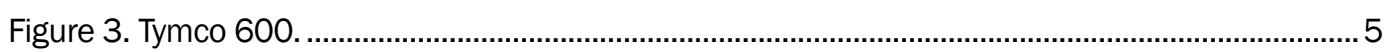

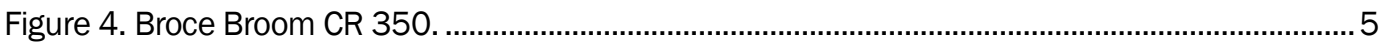

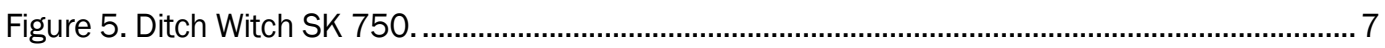

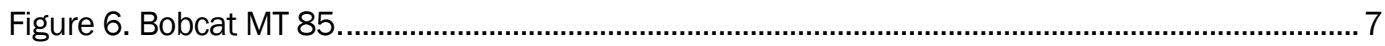

Figure 7. FOD Boss 8 Ground Force....................................................................................... 8

Figure 8. Tennant Sentinel............................................................................................... 8

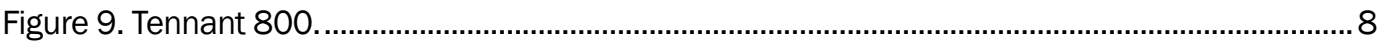

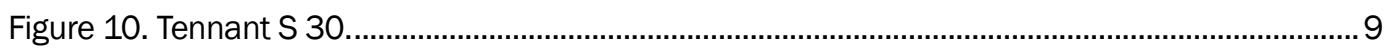

Figure 11. Equipment evaluation test site location. ..........................................................................10

Figure 12. Mock debris crater used in equipment evaluations........................................................11

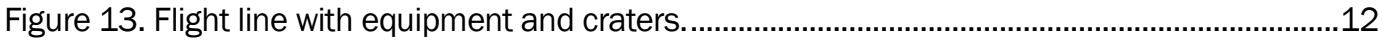

Figure 14. Broce Broom sweeping final debris. ........................................................................12

Figure 15. Orthomosaic image of the craters. ................................................................................14

Figure 16. Reconstructed digital elevation model of craters using photogrammetry.........................15

Figure 17. LiDAR in position for scanning scene. .........................................................................15

Figure 18. LiDAR scan depicting change detection, showing original crater and initial debris removal. .....................................................................................................................................

Figure 19. LiDAR scan showing final debris removal and sweep/vacuum equipment

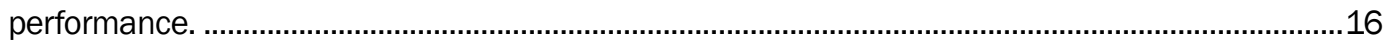

Figure 20. View of mock crater used in evaluation, with cavity outlined.........................................17

Figure 21. Sweep mark from CTL 279D with front broom................................................................18

Figure 22. Tymco 600 vacuum/sweep; medium gravel left behind. .................................................19

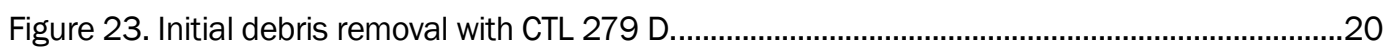

Figure 24. Passes from left to right: CTL Broom, FOD Boss, and Tymco. ..........................................20

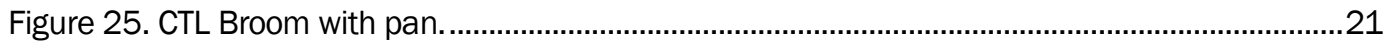

Figure 26. Tennant equipment with one pass and no brushes.........................................................22

Figure 27. Flight line after initial debris removal and before vacuum/sweep.....................................22

Figure 28. Tennant vacuum and brush activated in gravel..............................................................23

Figure 29. Final cleared lanes of Figure 28 at a different angle: 800 (right) and $\mathrm{S} 30$ (left)...........23

Figure 30. View from rear of Bobcat MT 85 showing width of bucket equal to track width. .............24

Figure 31. Broce broom passes: straight (left) and angled (right)...................................................25

Figure 32. Debris initial clearing equipment gross weight (red) and time to clear crater

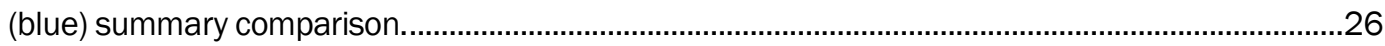

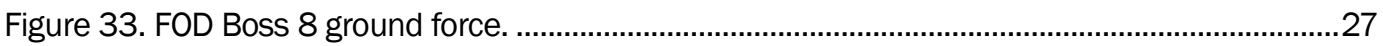




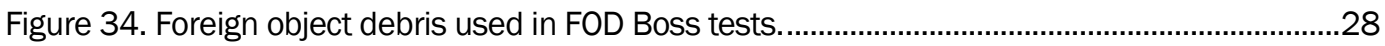

Figure 35. Sand debris subsurface in voids between aggregate. ....................................................29

Figure 36. Results from test 1...............................................................................................2

Figure 37. Large gravel placed at O-ft marker...........................................................................30

Figure 38. Wire rope placed at the 20-ft marker. ………................................................................30

Figure 39. Ammunition casings placed at 40-ft marker. .................................................................31

Figure 40. Random nuts, bolts, washers, chain, and metal placed at 60-ft marker.........................31

Figure 41. Results of one pass at slow speed with multiple types of FOD (Test 2)...........................32

Figure 42. Construction zone at airport. ................................................................................................33

Figure 43. Debris collected after construction zone test.....................................................................33

\section{Tables}

Table 1. Baseline equipment.

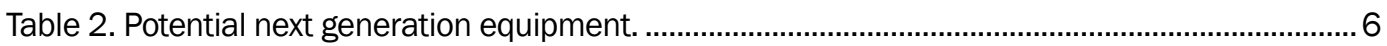




\section{Preface}

This study was conducted for the U.S. Air Force's Civil Engineer Modernization Program sponsored by Headquarters, U.S. Air Force Civil Engineer Center (AFCEC) at Tyndall Air Force Base, FL under Work Unit $\mathrm{BFK} 2 \mathrm{C} 4$. Dr. Craig Rutland, AFCEC, provided technical guidance and review during the project.

The work was performed by the Geotechnical Engineering and Geosciences Branch (GSG) of the Geotechnical and Structures Division (GSD) and the Engineering Systems and Materials Division (ESMD) Research Group, U.S. Army Engineer Research and Development Center, Geotechnical and Structures Laboratory (ERDC-GSL). At the time of publication, Chad A. Gartrell was Chief, GEGB; James L. Davis was Chief, GSD; Dr. Gordon W. McMahon was Chief, ESMD; and Pamela G. Kinnebrew was Technical Director for Military Engineering. The Deputy Director of ERDC-GSL was Dr. William P. Grogan, and the Director was Bartley P. Durst.

COL Bryan S. Green was the Commander of ERDC, and Dr. David W. Pittman was the Director. 


\section{Unit Conversion Factors}

\begin{tabular}{|c|c|c|}
\hline Multiply & By & To Obtain \\
\hline cubic feet & 0.02831685 & cubic meters \\
\hline cubic inches & $1.6387064 \mathrm{E}-05$ & cubic meters \\
\hline cubic yards & 0.7645549 & cubic meters \\
\hline degrees Fahrenheit & $(F-32) / 1.8$ & degrees Celsius \\
\hline feet & 0.3048 & meters \\
\hline foot-pounds force & 1.355818 & joules \\
\hline gallons (U.S. liquid) & 3.785412 E-03 & cubic meters \\
\hline $\begin{array}{l}\text { horsepower ( } 550 \text { foot-pounds force per } \\
\text { second) }\end{array}$ & 745.6999 & watts \\
\hline inches & 0.0254 & meters \\
\hline miles (U.S. statute) & $1,609.347$ & meters \\
\hline miles per hour & 0.44704 & meters per second \\
\hline pounds (force) & 4.448222 & newtons \\
\hline pounds (force) per foot & 14.59390 & newtons per meter \\
\hline pounds (force) per inch & 175.1268 & newtons per meter \\
\hline pounds (force) per square foot & 47.88026 & pascals \\
\hline pounds (force) per square inch & 6.894757 & kilopascals \\
\hline slugs & 14.59390 & kilograms \\
\hline square feet & 0.09290304 & square meters \\
\hline square inches & 6.4516 E-04 & square meters \\
\hline square miles & $2.589998 E+06$ & square meters \\
\hline square yards & 0.8361274 & square meters \\
\hline tons (force) & $8,896.443$ & newtons \\
\hline tons ( 2,000 pounds, mass) & 907.1847 & kilograms \\
\hline tons ( 2,000 pounds, mass) per square foot & $9,764.856$ & kilograms per square meter \\
\hline yards & 0.9144 & meters \\
\hline
\end{tabular}




\section{Introduction}

\subsection{Background}

The Airfield Damage Repair (ADR) Modernization Program was initiated to improve and expand the U.S. Air Force's (USAF's) ability to perform airfield pavement repair tasks to support the operation of modern aircraft for a variety of mission scenarios. The ADR Modernization Program includes the repair of airfields and associated paving surfaces damaged by munitions such as bombs or missile attacks. ADR encompasses all the tasks required to establish, sustain, or recover airfield infrastructure to support aircraft operations in contingency environments. The objective of the ADR Modernization Program is to develop and procure materials and equipment required to successfully meet mission requirements for the full spectrum of scenarios.

The U.S. Army Engineer Research and Development Center (ERDC) has been developing technical solutions for modernizing the USAF's ADR process for almost a decade. Previous research identified new materials, equipment, and processes that provide the USAF with a completely modernized and scalable ADR solution for a suite of mission scenarios. This modernizing process is ever changing and continues as supportive technologies advance. A part of the ADR modernization is the requirement for deployable and more efficient debris removal equipment. The current USAF capability does not possess adequate equipment to meet the new requirements of advanced threats. Thus, innovative, more efficient equipment is required to supplement existing equipment.

\subsection{Objective and scope}

The objective of this project is to investigate and identify efficient commercial debris removal techniques and equipment that are adaptable to military mission requirements and easy to deploy and that can rapidly accomplish removal of airfield debris based on current threats. 
The scope of this work follows five steps with close coordination with the U.S. Air Force Civil Engineer Center (AFCEC):

1. Characterize current debris removal baseline procedures and equipment,

2. Determine USAF problems with existing baseline equipment and develop minimum requirements for next generation debris removal systems,

3. Conduct market research to identify commercial technologies that can be adopted and adapted to meet next generation requirements,

4. Evaluate new candidate technologies in meeting these requirements, and

5. Develop and document specifications for new systems to support procurement.

\subsection{Current debris removal baseline procedures and equipment}

The current debris removal baseline procedures and equipment are provided in Interim Tactics, Techniques, and Procedures (TTP), Airfield Damage Repair (ADR) interim process for recovery after attack (2015). The first step in crater repair is debris removal from an identified repair zone. The debris removal team may also be tasked to support the minimum available operating surface (MAOS) foreign object debris (FOD) prevention. The FOD team is responsible for removing small to large debris from repair areas and access routes and final sweeping before air traffic begins. The FOD may be augmented with debris removal equipment and compact track loaders (CTLs) with brooms.

\subsection{Crater repair tasks}

The following steps must be completed to repair craters:

- Step 1. Clear debris from around all crater repair zones. CTL and loader can assist if heavy debris slows operation.

- Step 2. Using a loader, push debris to the side of the minimum operating strip (MOS) (30 ft off MOS, pile height not to exceed 36 in.).

- Step 3. Once debris is clear from around craters, clear all areas in the repair zone.

- Step 4. During crater excavation, remove excavated debris.

- Step 5. Remove broken pavement ahead of the repair as needed.

- Step 6. Using the loader, load excavated debris into dump trucks for site removal. 
The baseline equipment to accomplish these tasks is a grader, a dozer, a loader, a tractor with a broom, and a vacuum sweeper (CTL with broom attachments).

\subsection{USAF problems with existing baseline equipment and minimum requirements for next generation debris equipment}

Mobilization of the current debris removal equipment in the field is a problem for rapid air transported deployment. Based on the size, shape, and weight of the current ADR debris removal equipment, the inability to readily transport the larger machines due to weight and size restrictions is an issue. The focus of this study is to identify and evaluate the use of smaller debris removal equipment that can accomplish the mission in an expedient manner. While the overall debris removal time may be longer, having the ability to mobilize with ease may outweigh advantages of the existing larger equipment and its logistical deployment limitations. The multiple smaller pieces of equipment tested in this study has the potential of producing positive results when executing the ADR tasks. 


\section{Baseline Equipment}

The baseline equipment in this study is for debris clearance operations of scraping (plowing), sweeping, and vacuuming; its use for debris excavation and loading was not a focus in this study. However, some baseline equipment and those considered as next generation have the capability to excavate and load under certain conditions.

The baseline equipment is tabulated in Table 1 and shown in Figures 1 through 4 .

Table 1. Baseline equipment.

\begin{tabular}{|l|c|c|c|c|}
\hline Manufacturer & Komatsu & Caterpillar & Broce & Tymco \\
\hline Model & WA 150 & 279D & CR 350 & 600 \\
\hline Power (hp) & 95 & 79.2 & 85 & 215 \\
\hline Max Travel Speed (mph) & 24 & 7 & $\begin{array}{c}\text { Low 13 } \\
\text { High 34 }\end{array}$ & 10 \\
\hline Width over Tires (in.) & 87.6 & 78 & 96 & 97 \\
\hline Overall Height (in.) & 121.2 & 83.2 & 100 & 118 \\
\hline Operating Weight (lb) & 18,453 & 9,893 & 5,000 & 20,214 \\
\hline
\end{tabular}

Figure 1. KOMATSU WA 150 loader.

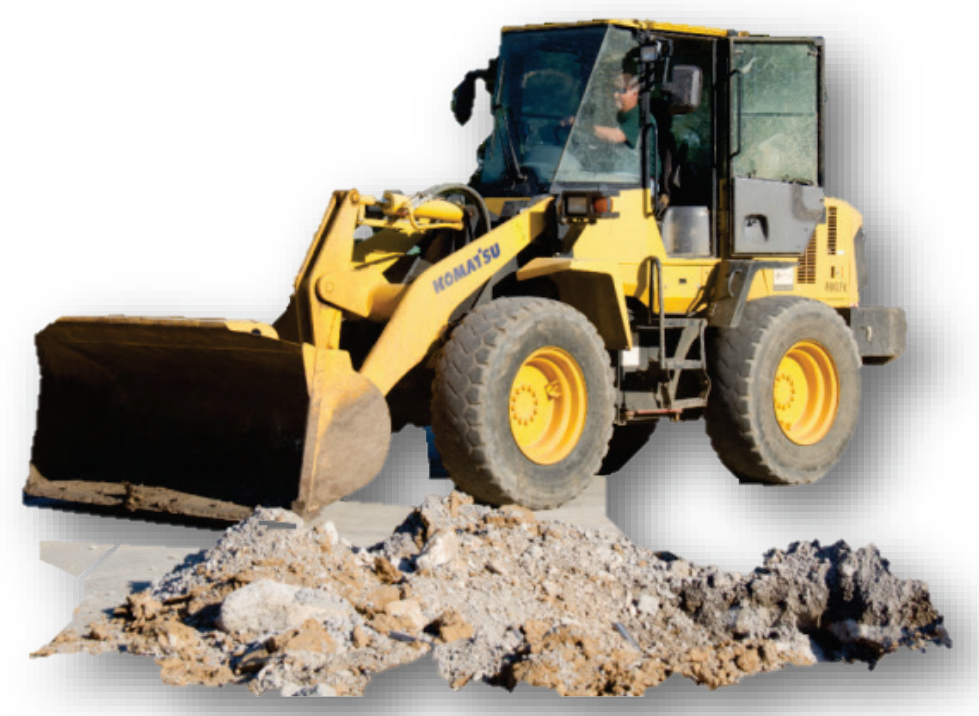


Figure 2. Caterpillar 279D.

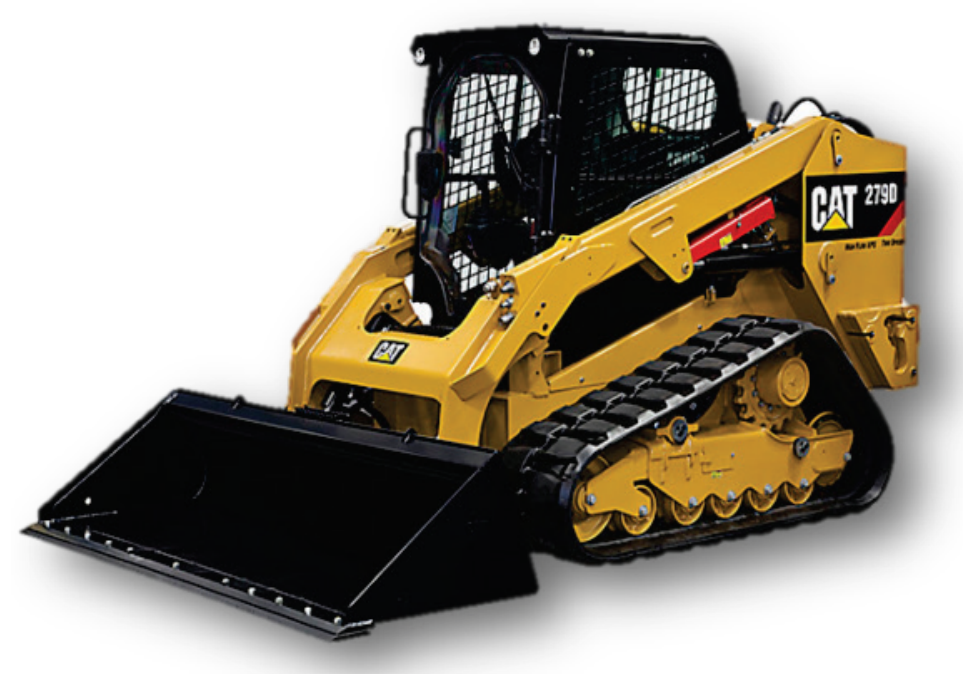

Figure 3. Tymco 600.

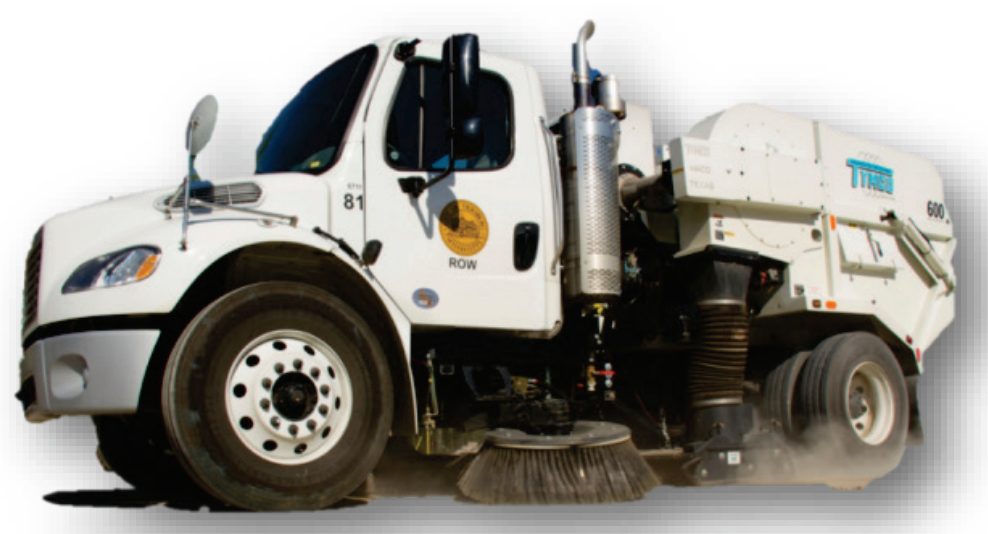

Figure 4. Broce Broom CR 350.

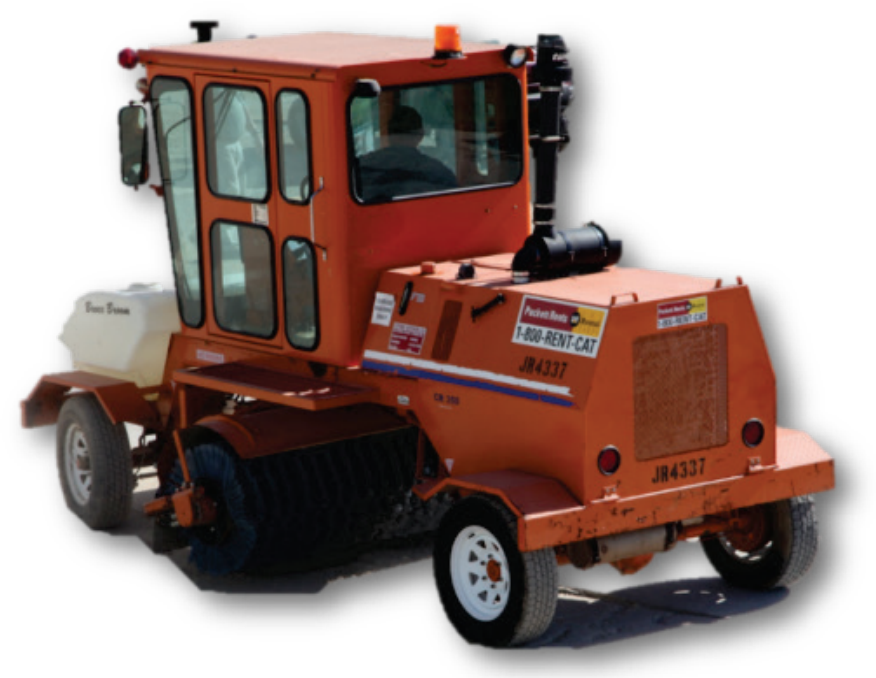




\section{Market Research for Potential Next Generation Equipment}

Market research was conducted to identify commercial technology that can be adopted and adapted to meet next generation requirements for debris removal equipment with a reduced logistical footprint and performance characteristics relevant to the ADR mission. For this initial data collection effort, equipment with a maximum weight capacity of approximately 4,00o lb was considered. Pertinent physical dimensions, operational characteristics, and effectiveness information for potential equipment solutions were assembled. Each debris removal equipment solution was evaluated for physical dimensions (ability to fit within the cargo limitation of a C-130) and operational capacity (ability to perform common ADR tasks) per the published technical data sheets. A summary of identified equipment alternatives is presented in Table 2, and photographs of each test vehicle are presented in Figures 5 through 10.

Note that this study attempted to obtain a representative cross section of various equipment manufacturers; therefore, the provided data should not be considered all inclusive. Other manufacturers and/or models that are not included in this report may exist.

Table 2. Potential next generation equipment.

\begin{tabular}{|l|c|c|c|c|c|c|}
\hline Manufacturer & $\begin{array}{c}\text { Ditch } \\
\text { Witch }\end{array}$ & Bobcat & $\begin{array}{c}\text { FOD } \\
\text { Boss }\end{array}$ & Tennant & Tennant & Tennant \\
\hline Model & SK 750 & MT 85 & 8 GF & Sentinel & 800 & S30 \\
\hline Power (hp) & 24.8 & 25 & & 99 & 65 & 24.8 \\
\hline $\begin{array}{l}\text { Operating Weight (Ib) } \\
\text { (no attachment) }\end{array}$ & 2,890 & 3,110 & 65 & 12,500 & 6,500 & 3,570 \\
\hline Length with Bucket & 105 & 106.2 & $\mathrm{n} / \mathrm{a}$ & 206 & 120 & 93 \\
\hline Width over Tires (in.) & 43 & 35.6 & 12 & 70 & 70 & 62.5 \\
\hline Overall Height (in.) & 57 & 54.6 & 10 & 100 & 52.5 & 58 \\
\hline Max Travel Speed (mph) & 4.7 & 4 & 25 & 14 & 10 & 15 \\
\hline Diesel & $\mathrm{Y}$ & $\mathrm{Y}$ & $\mathrm{n} / \mathrm{a}$ & $\mathrm{Y}$ & $\mathrm{Y}$ & $\mathrm{Y}$ \\
\hline
\end{tabular}


Figure 5. Ditch Witch SK 750.

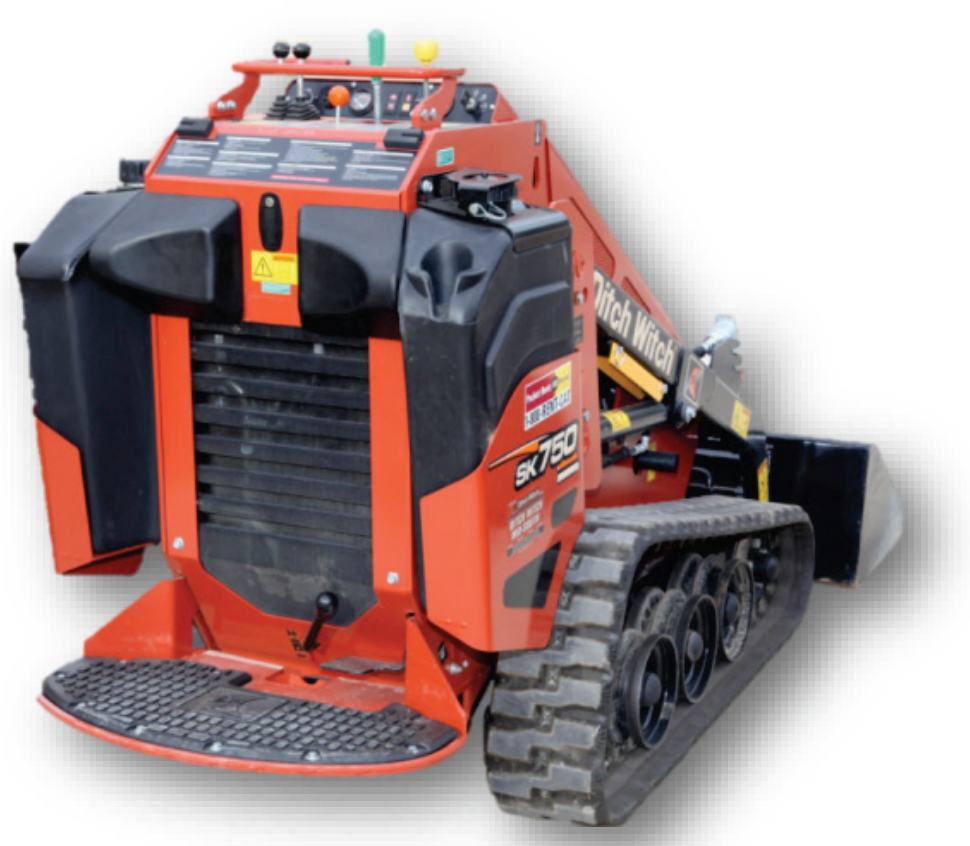

Figure 6. Bobcat MT 85.

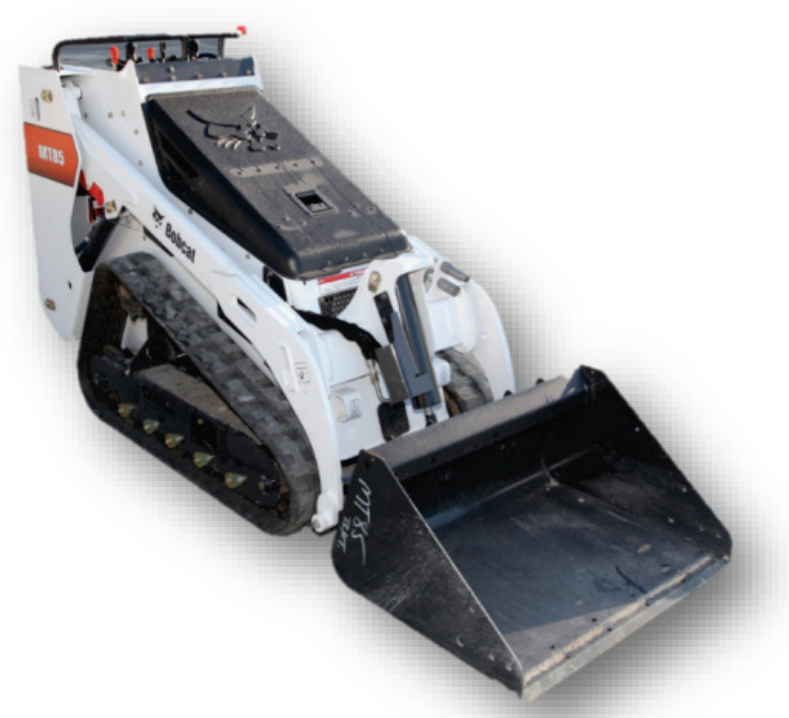


Figure 7. FOD Boss 8 Ground Force.

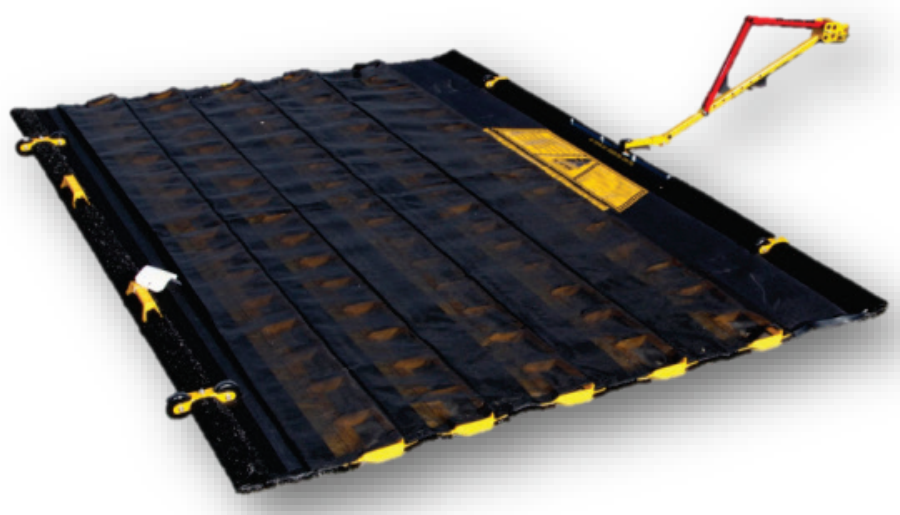

Figure 8. Tennant Sentinel.

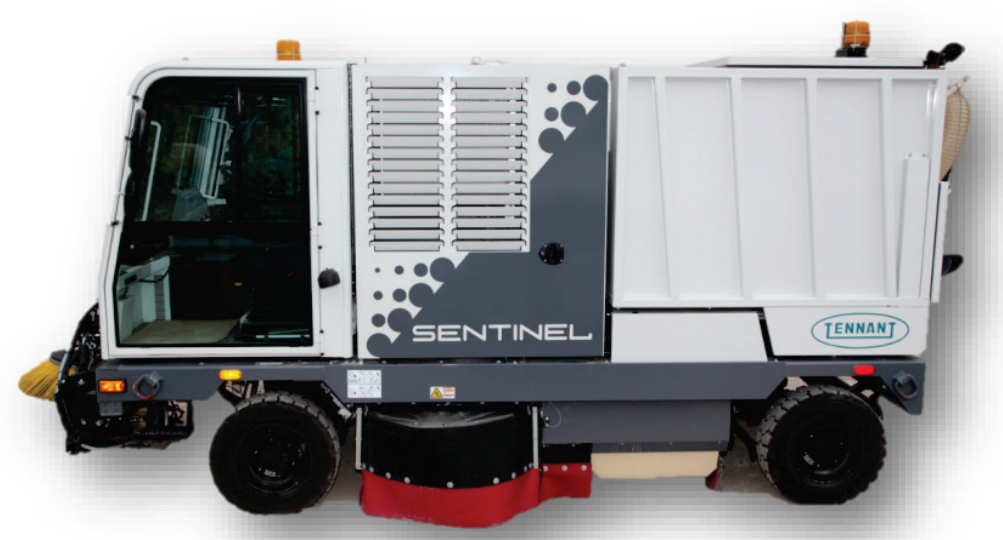

Figure 9. Tennant 800.

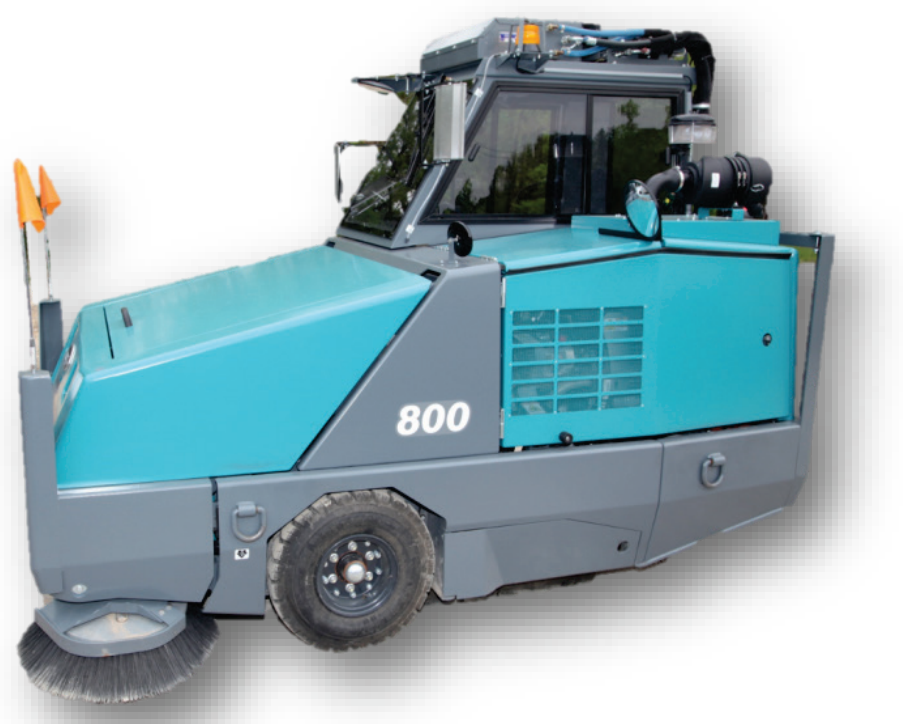


Figure 10. Tennant S 30.

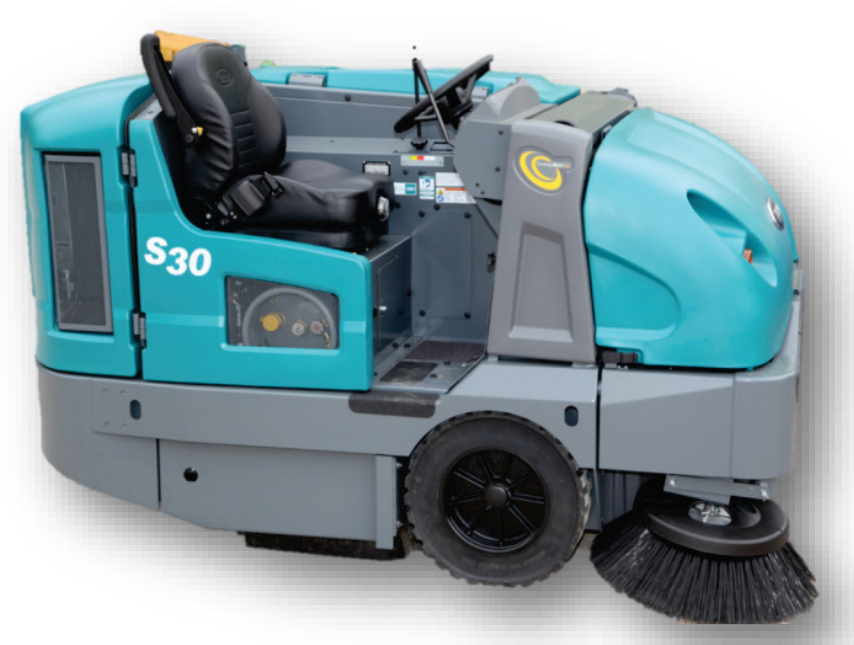

Overall height, width, and operating weight information were collected for each component of debris removal equipment and compared to published cargo characteristics of a C-130. Review of the AMC affiliated contingency load planning workbook 36-101 Volume 2 (2014)(Air Mobility Control Unit 2003) provided the following maximum cargo characteristics for a C-130: 102 in. in height, $115 \mathrm{in}$. in width, $612 \mathrm{in.} \mathrm{in} \mathrm{length,} \mathrm{and} \mathrm{25,000} \mathrm{lb} \mathrm{in}$ allowable cabin load. These dimensions may be exceeded after coordination with mission planning personnel. All equipment tested is $\mathrm{C}-130$ transportable since the physical dimensions were less than the published maximum cargo dimensions. The craters are simulations and may tend to include a more dense debris array than an actual blast. The timed events were conducted in non-chemical, temperate weather during daylight hours. 


\section{Equipment Evaluation Test Procedures}

\subsection{Test site location}

The equipment evaluation test site was located in the northeast sector of the ERDC facility in Vicksburg, MS (Figure 11). The area of interest simulates a runway for aircraft. The approximate size of the test site is $90 \mathrm{ft}$ by $90 \mathrm{ft}$ by $18 \mathrm{in}$. A crater was constructed with a diameter of $8 \mathrm{ft}$ and a depth of $2 \mathrm{ft}$ for the simulation. Another 8-ft-diam crater was constructed for debris removal and did not contain a concave center. The mock debris crater used in the equipment evaluations is shown in Figure 12.

Figure 11. Equipment evaluation test site location.

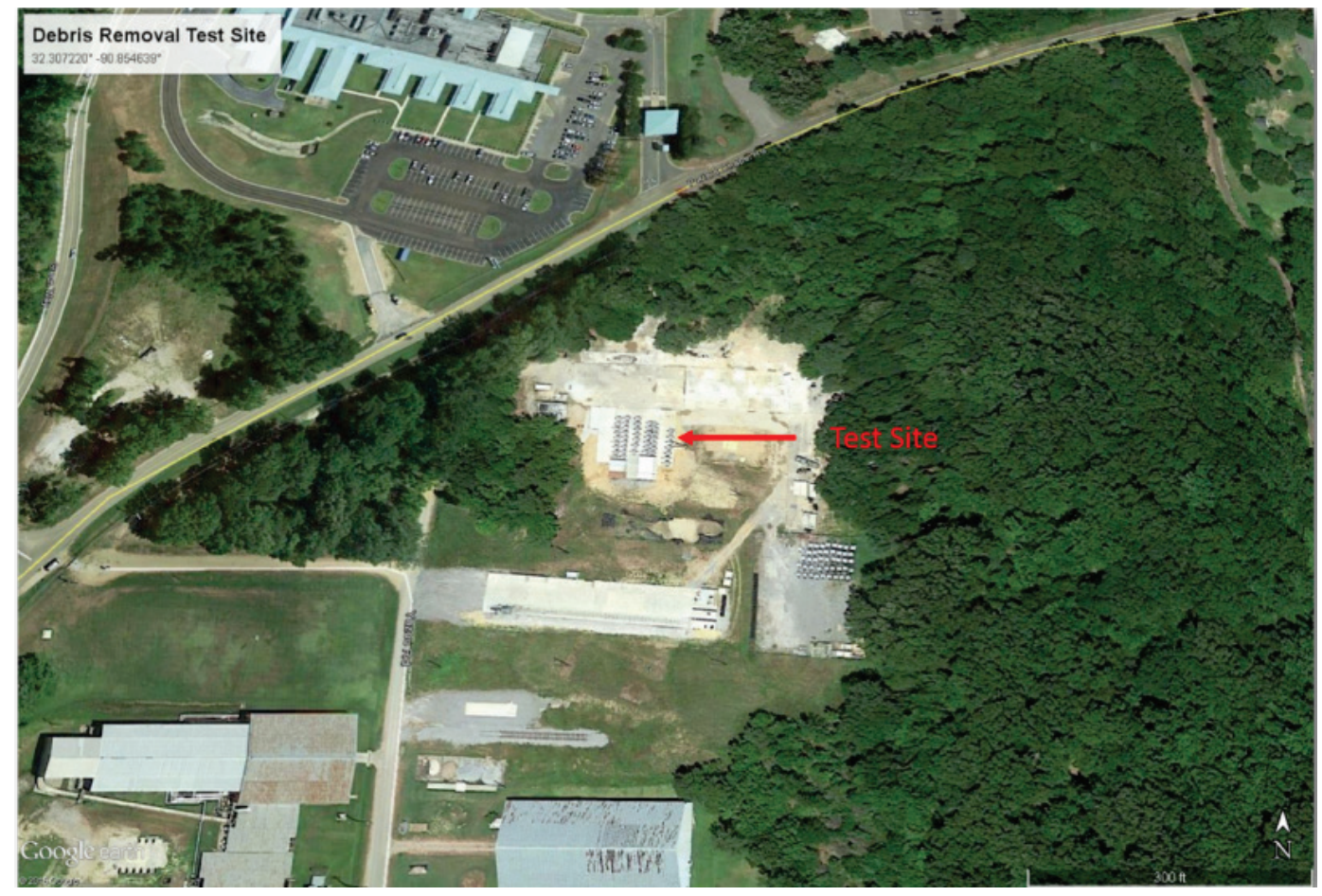


Figure 12. Mock debris crater used in equipment evaluations.

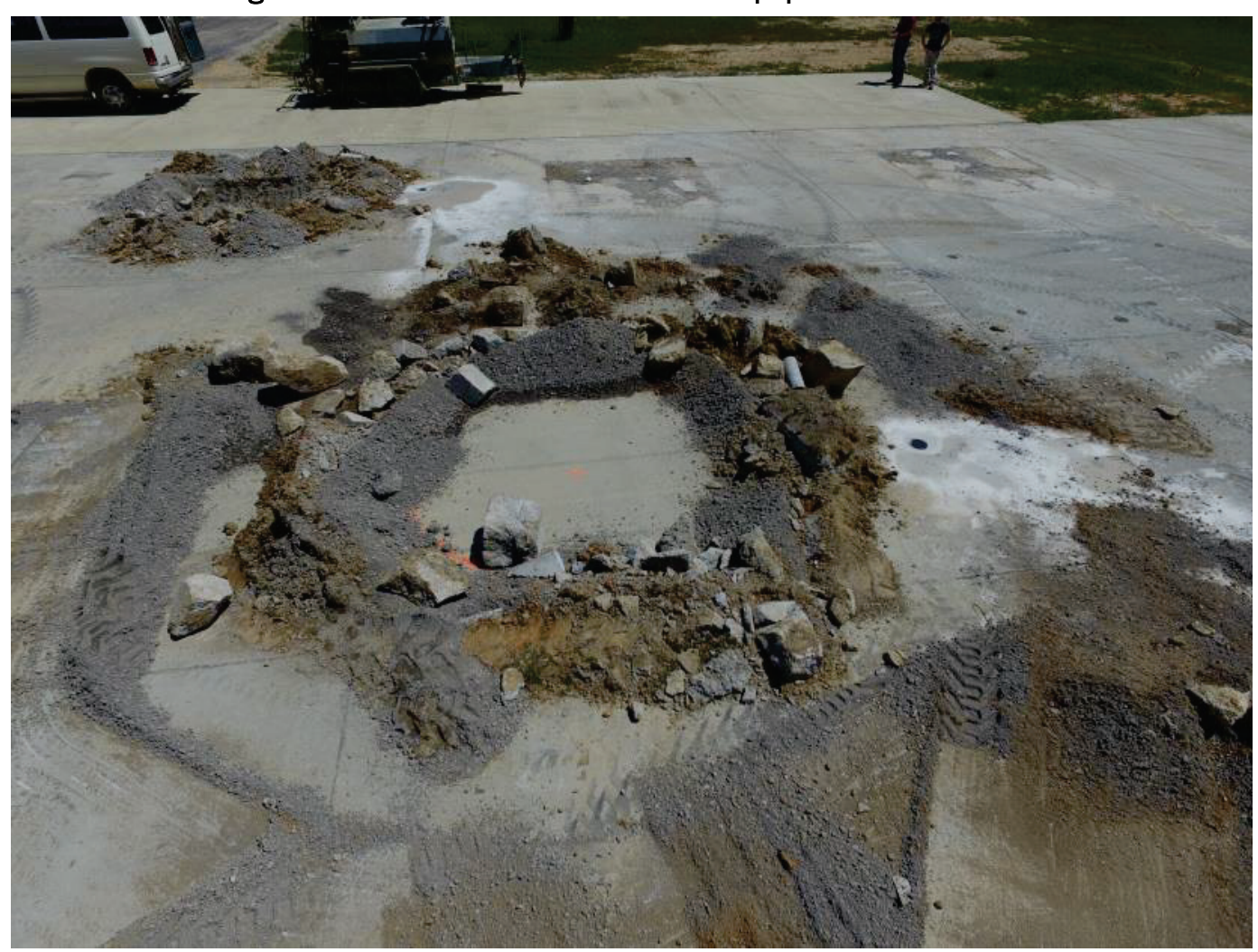

\subsection{Initial debris removal evaluation}

Loaders cleared the debris away from the crater by lowering the front bucket and setting the bottom blade at a 45-deg angle. The debris was pushed approximately $30 \mathrm{ft}$ away, and the pile was no higher than $3 \mathrm{ft}$. Loaders cleared all material, leaving behind as little as possible. The baseline equipment used was the Komatsu WA 150 and the Caterpillar

CTL 279D. For the evaluation of new candidate technology, the Ditch Witch SK 750 and the Bobcat MT 85 were tested. The evaluation setup is shown in Figure 13 with a flight line of equipment starting from the existing baseline on the right and transitioning to the candidate next generation debris removal equipment, with the test debris crater in foreground. 
Figure 13. Flight line with equipment and craters.

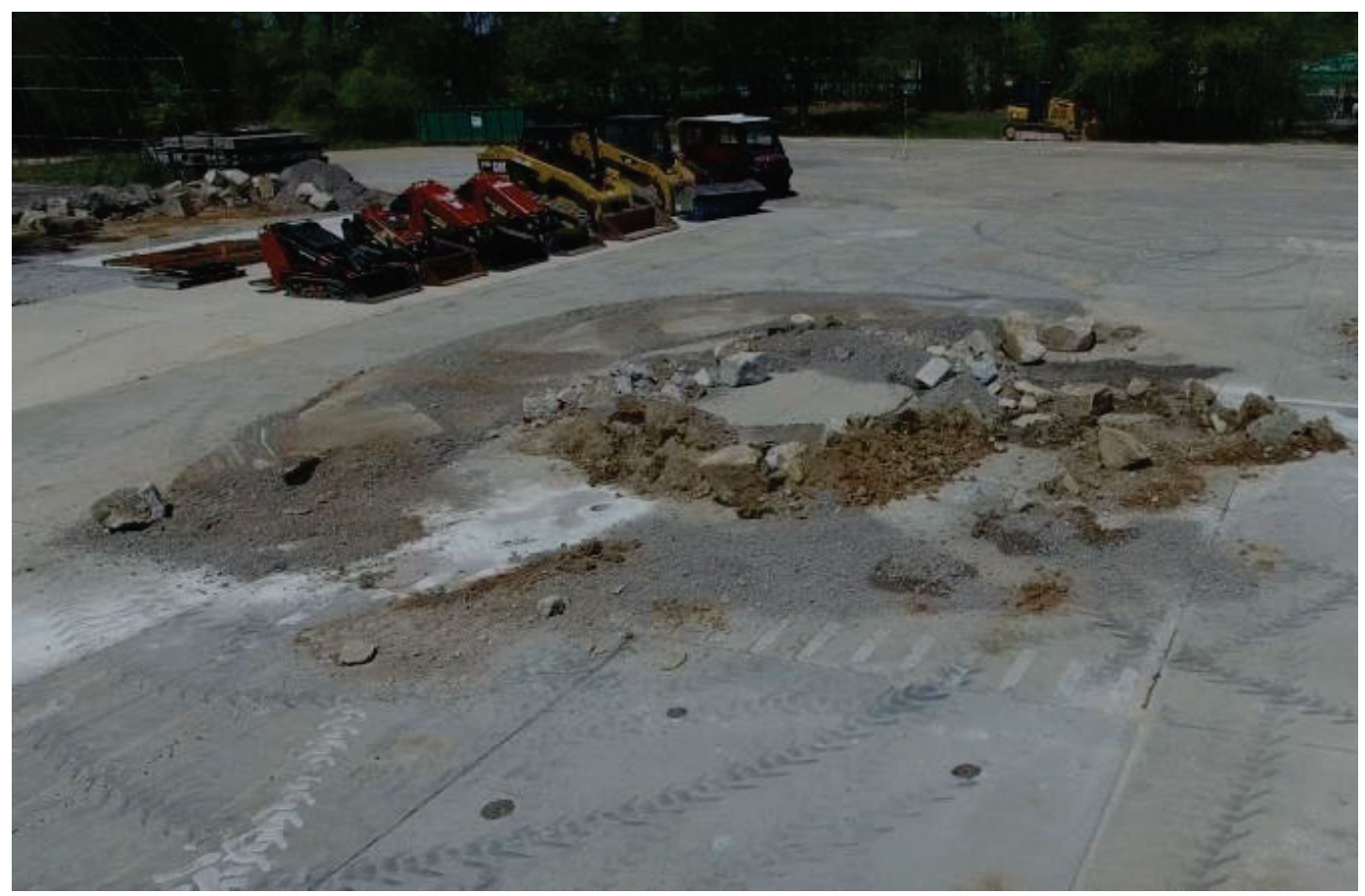

\subsection{Final debris removal evaluation}

Sweepers and vacuums followed up to make sure no small debris or FOD remained. An important distinction between a kick broom operation and sweeper/vacuum equipment is the potential dust generation and its effect on working conditions, as shown in Figure 14. Also, the sweeping operation only moves the loose material and will involve several passes to move the material to the side where a vacuum captures the material in one pass.

Figure 14. Broce Broom sweeping final debris.

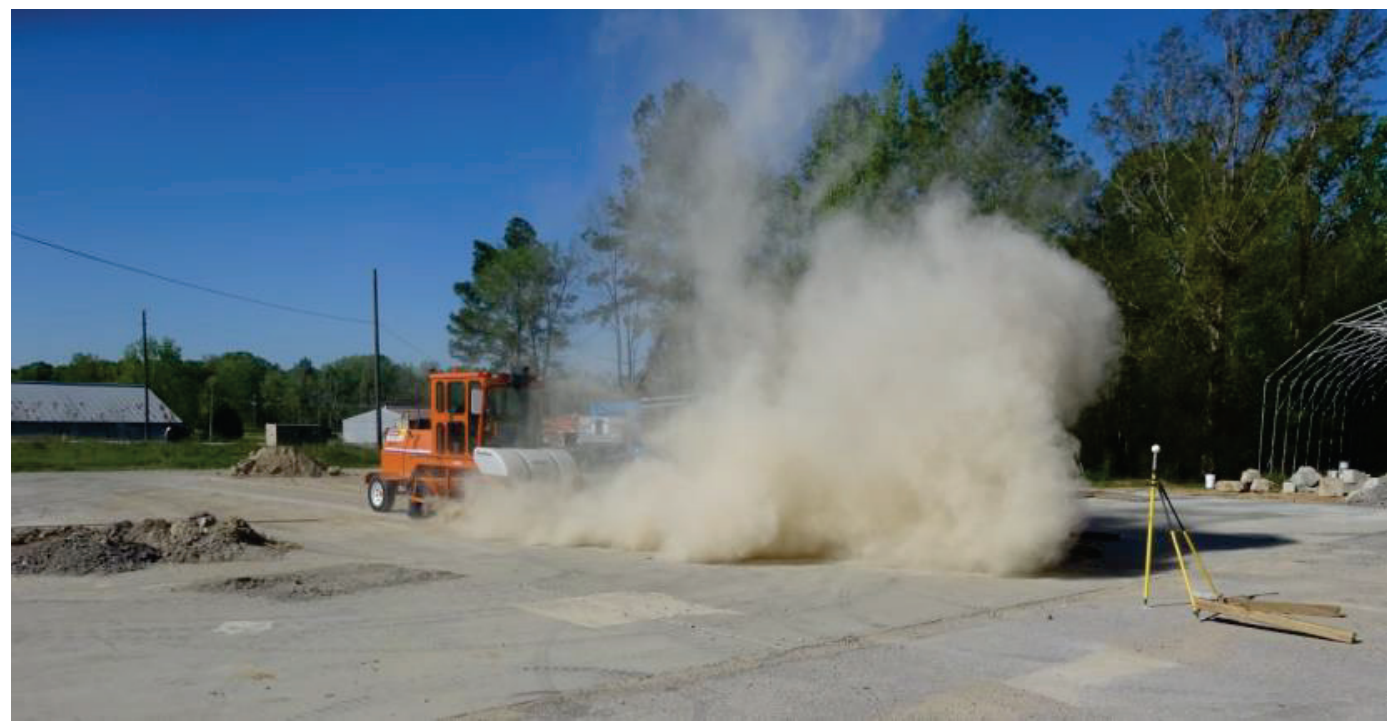




\subsection{Test methods for quantification of equipment performance}

As part of this effort, two remote sensing geomatic (geospatial) technologies, photogrammetry and LiDAR (Light Detection and Ranging), were employed to assist in characterizing and quantifying the performance of the debris removal equipment. This was a stretch objective to assess its potential use in debris volume and characterization mission assessment. This technique can be useful for measuring the volume of a crater poststrike. For example, measuring the volume of the crater will allow the crater-repair chief to call for a specific amount of fill. This will save time by eliminating excess dumping of fill by the trucks, causing extra trips.

While these two methods are basically generating the same final digital elevation model, each has its distinct strengths and constraints, and some applications may need both to meet the mission requirements.

Photogrammetry. Photogrammetry is basically processing overlapping photographs with the requisite accompanying information to enable stereo viewing; produce a mosaic image of the area of interest; and calculate $\mathrm{x}, \mathrm{y}, \mathrm{z}$ position data of the ground surface and features of interest. The individual photographs were perspective-rectified to an overhead perpendicular field of view (vertical overhead). The raw photographs were acquired from a mobile scissor jack platform at approximately $20 \mathrm{ft}$ in height. This application used a Canon EOS 5D Mark III (28-mm focal length) with a pixel resolution of $5760 \times 3840$ to create an orthographic photo-mosaic survey of the test site and provide a digital elevation model of the craters. The pixel size was $6.44 \times 6.44$ microns. Point cloud generation consisted of 19,512 points with 101 images taken, and the coordinate system was world geodetic system 84 . The resulting orthomosaic image and the digital elevation model are shown in Figures 15 and 16, respectively.

LiDAR. The LiDAR data collection is basically scanning an area of interest with a laser rangefinder to generate a point cloud of $\mathrm{x}, \mathrm{y}, \mathrm{z}$ data, which is the basis for developing the 3-D surface model for the area of interest. The procedure involves deploying the laser scanner at several locations around the perimeter of the study area. Collection of multiple overlapping scan locations and placement of geo-referenced targets in each scan enable the points to be precisely located, resulting in a digital elevation data set (point cloud) with a sampling of 5 to $10 \mathrm{~mm}$ that, after processing, result in an elevation model with a spatial resolution of $25 \mathrm{~cm}$. Figure 17 shows the LiDAR scanner placed to scan the craters. Figures 18 and 19 are example 
extracted data points, processed and displayed surface elevation models for the debris crater. Figure 18 is a change detection image that is a composite of two color-coded data sets, with green representing the starting debris crater and yellow representing the debris scraped out of the MOS. (1-green) starting debris crater and (2-yellow) after the debris is scraped out of the MOS. The green layer is a depiction of the crater poststrike (no remediation). The yellow section is the debris after the initial debris clearance. In Figure 19 the lanes swept are easily seen, showing the high degree of resolution possible with this method.

Figure 15. Orthomosaic image of the craters.

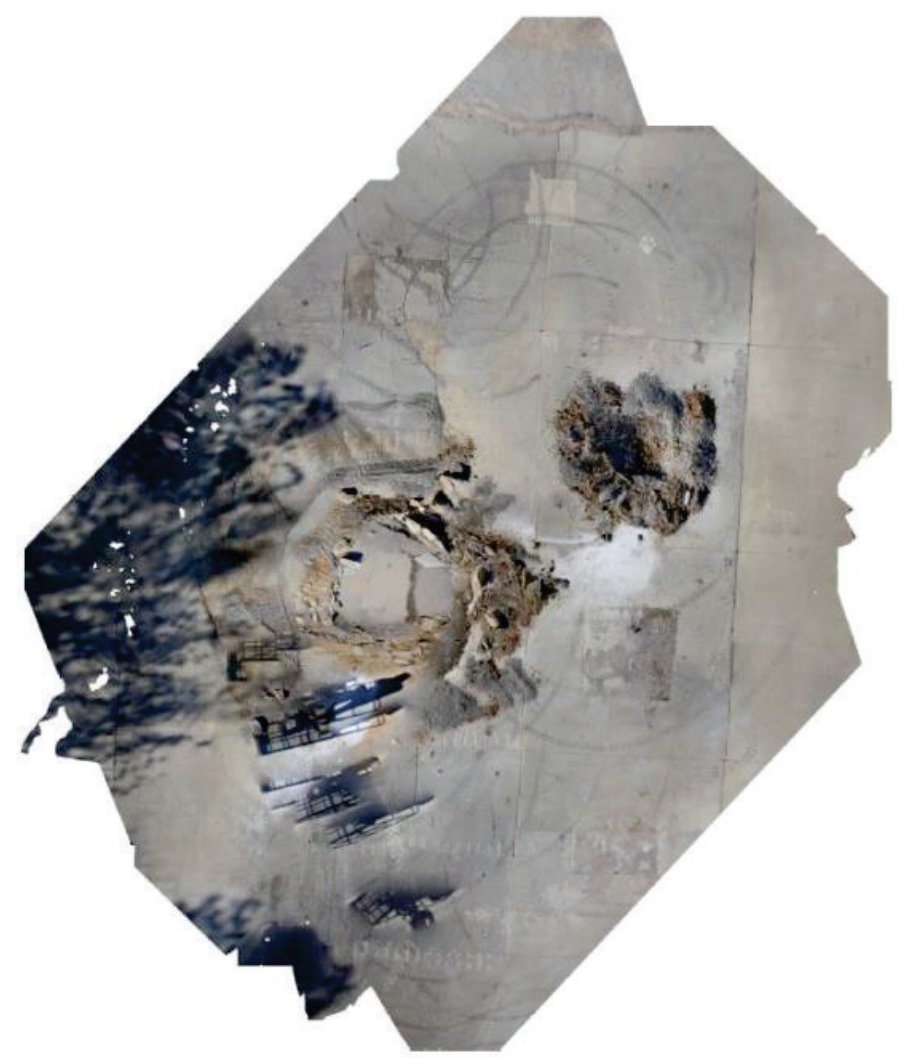


Figure 16. Reconstructed digital elevation model of craters using photogrammetry.

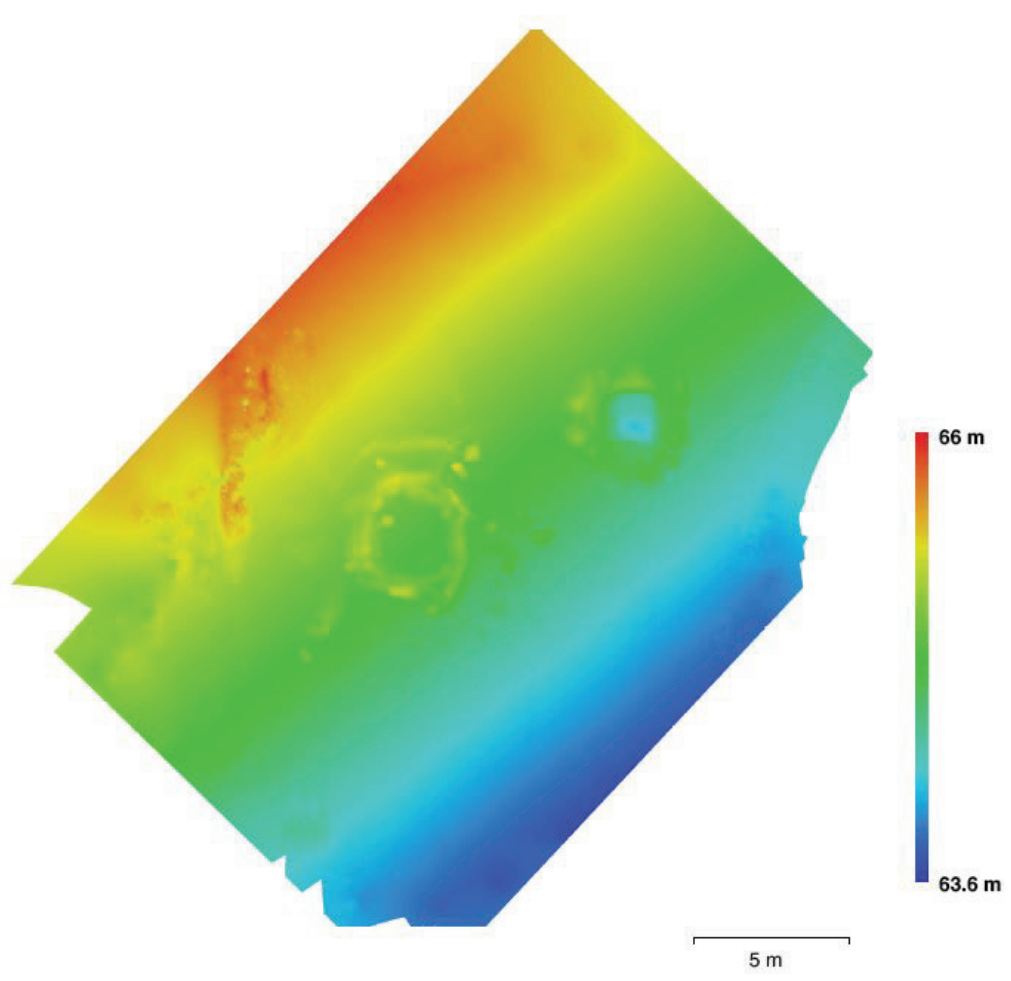

Figure 17. LiDAR in position for scanning scene.

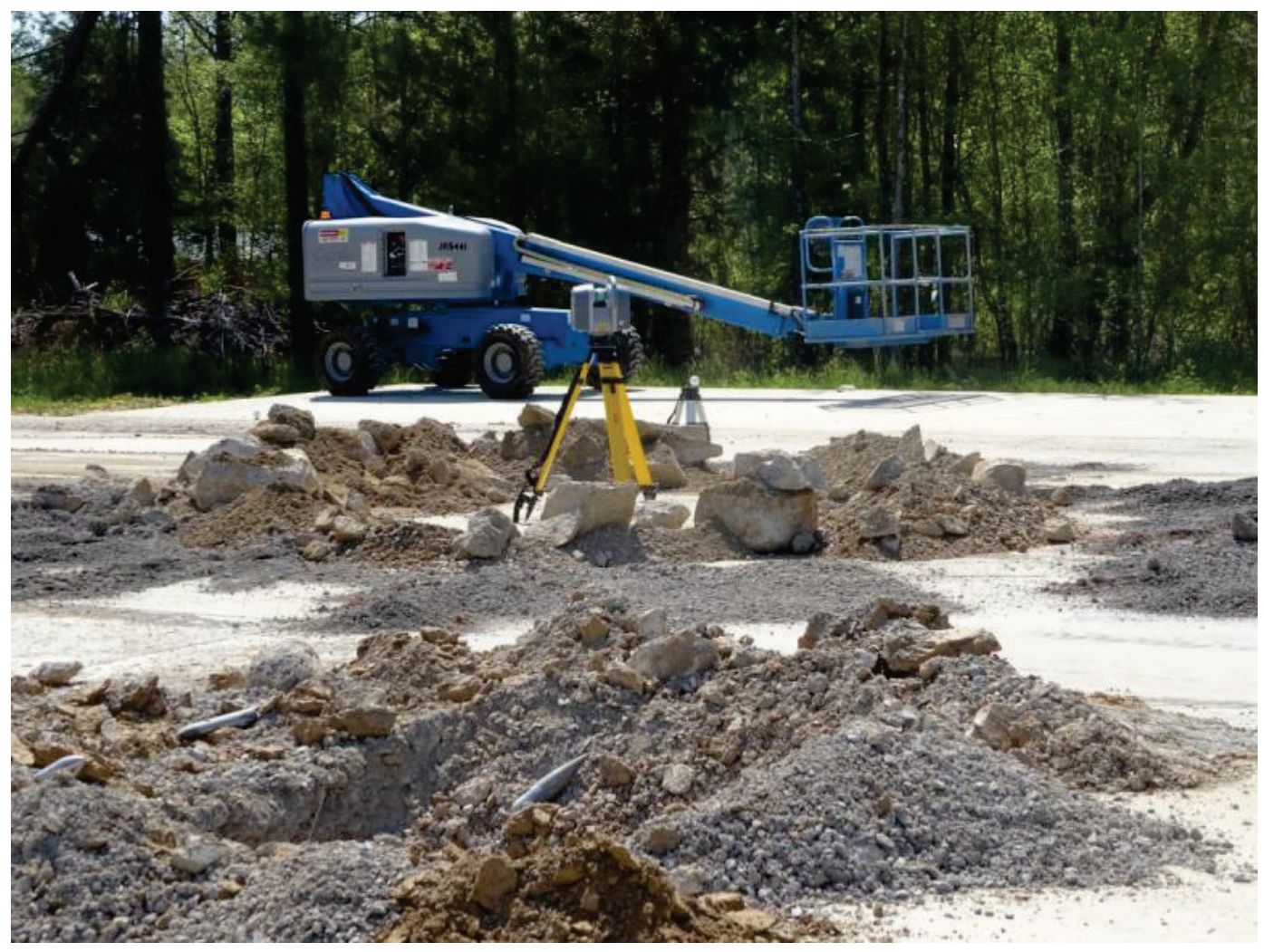


Figure 18. LiDAR scan depicting change detection, showing original crater and initial debris removal.

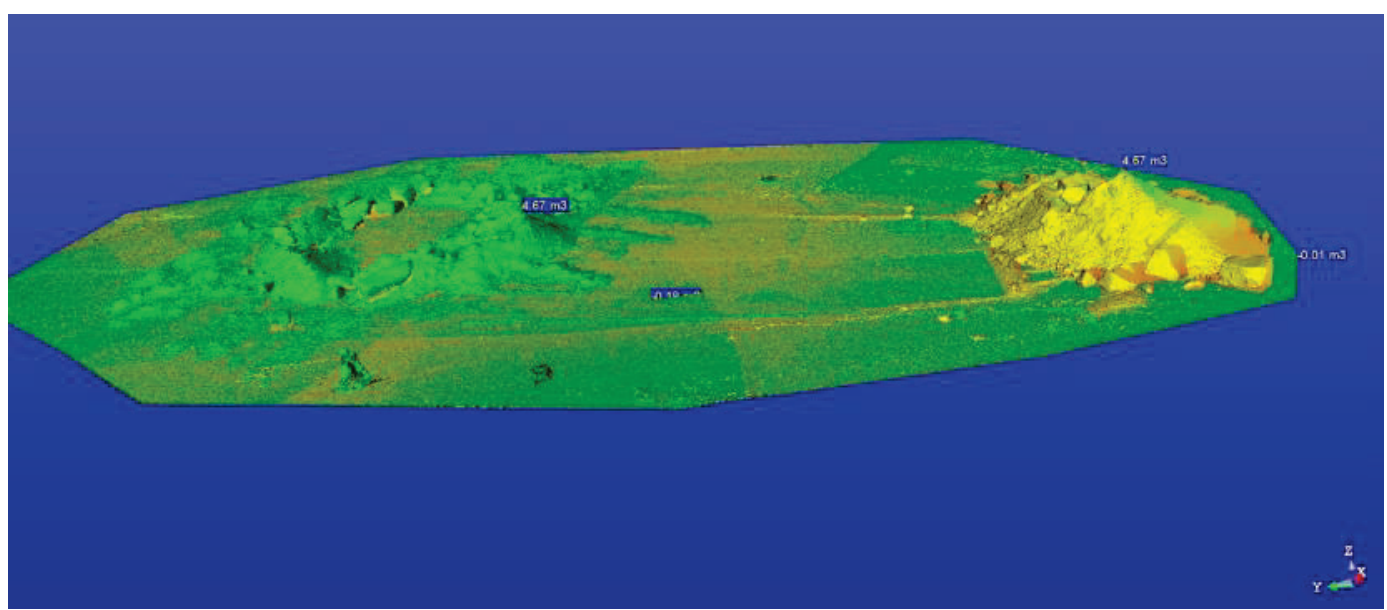

Figure 19. LiDAR scan showing final debris removal and sweep/vacuum equipment performance.

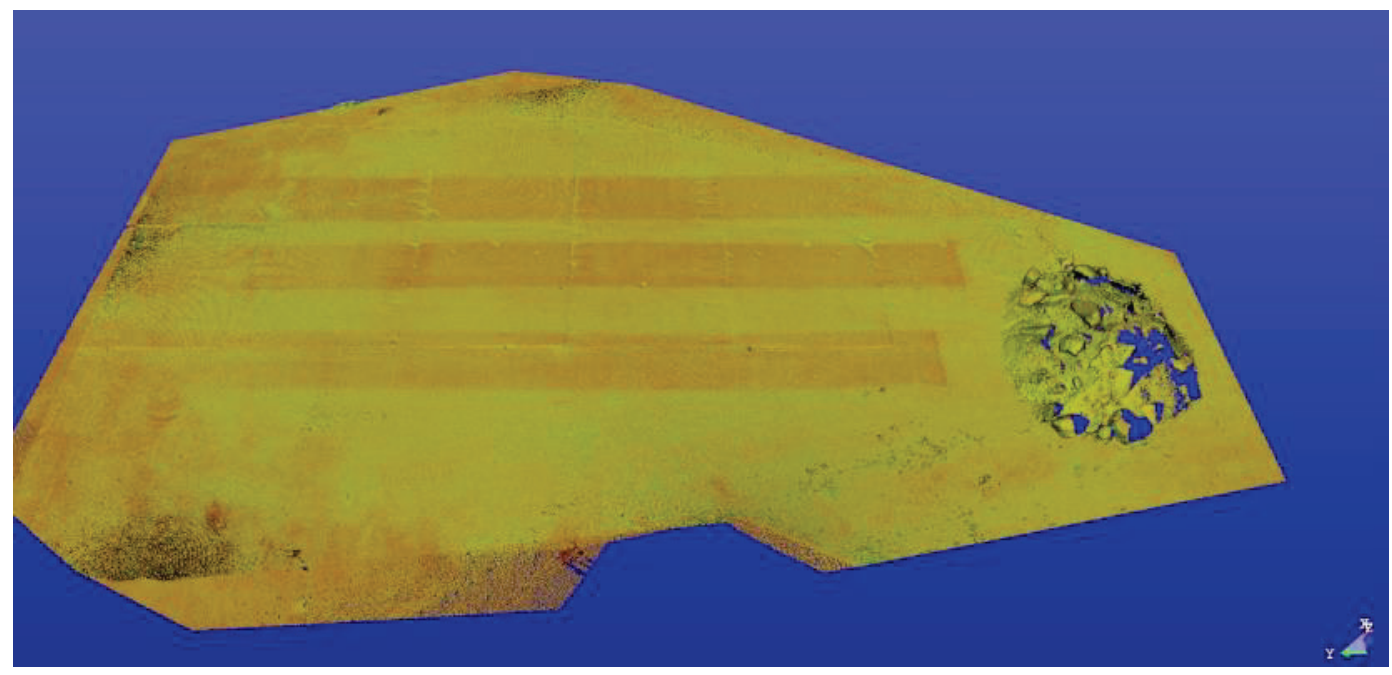




\section{Field Evaluation and Results}

\subsection{Field evaluation}

A field evaluation of selected commercial-off-the-shelf (COTS) debris removal equipment was performed. The evaluation consisted of testing each component's ability in a realistic environment to perform the typical ADR two-step task of initial debris removal and final debris removal. The evaluation included compilation of equipment technical specifications and evaluation of speed, maneuverability, and ultimately timed trials to accomplish the debris removal task. The mock crater used for all debris removal tests was without an actual cavity to avoid pushing material into the crater. The simulated crater had a border marked with paint to signify the crater cavity (Figure 20). The cleared initial debris was moved $30 \mathrm{ft}$ away as in the prescribed procedures in preparing the runway for final debris equipment implementation. The initial debris removal tests were conducted with one mini CTL. The last initial debris removal test was conducted with two mini CTLs to measure crater clear time; they showed promising results. After each test, the crater was reconstructed from the push material of the previous crater, resulting in close volumetric earthen measurements. The Toro Dingo 525 and the Ditch Witch SK 350 were initially used in the experiment. It was found that these were not practical in initial debris removal due to their reduced size and power.

Figure 20. View of mock crater used in evaluation, with cavity outlined.

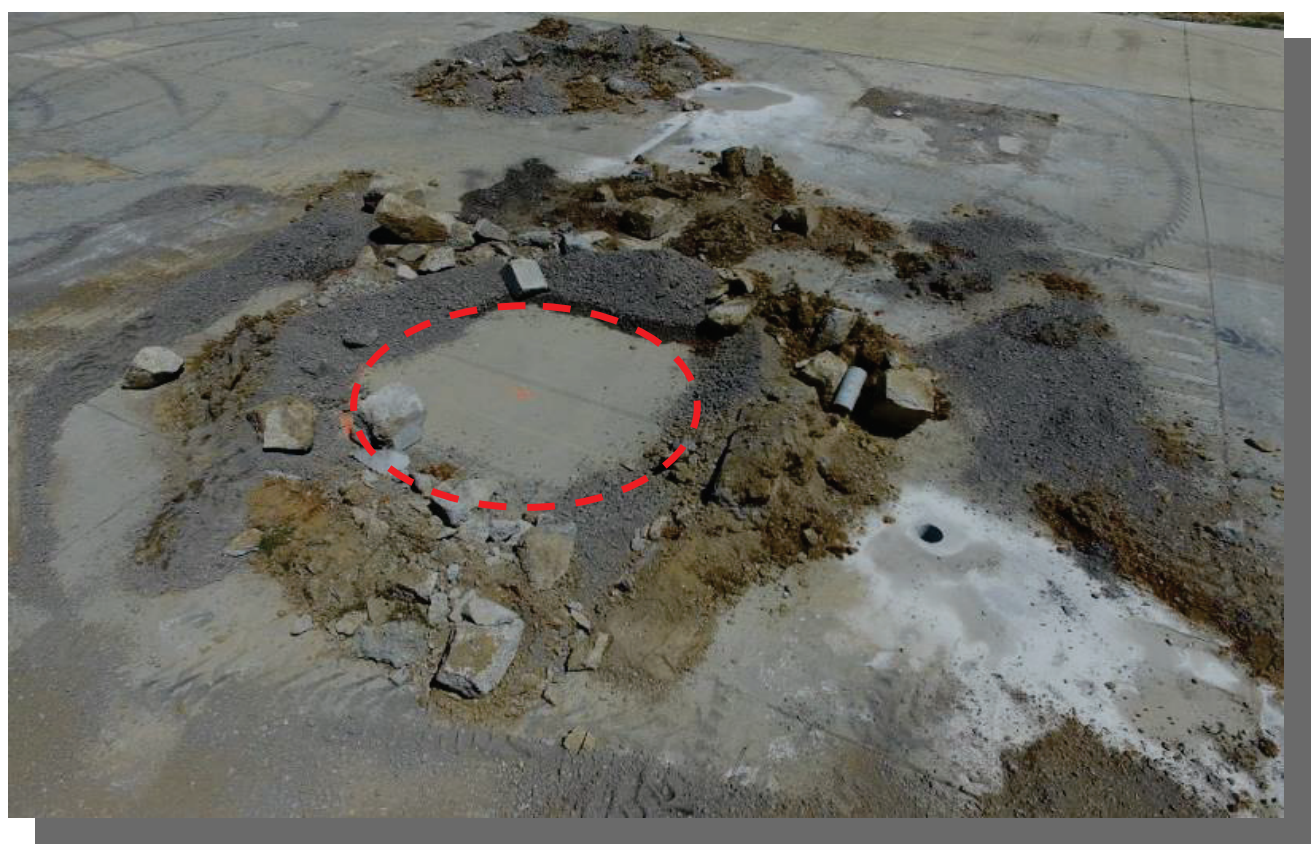




\subsection{Test 1}

Test 1 was conducted with the Komatsu WA 150 baseline loader. The crater clearing process involved the loader orienting the bucket blade at approximately 45 deg to the runway and pushing the debris forward to its final location. A timed test was conducted along with the collection of LiDAR and photographic data to measure and evaluate clearing effectiveness. The time for the Komatsu to accomplish the initial debris clearance of the crater was 6:10 min. After the initial removal of debris, a broom was evaluated for final debris removal. The 279D compact track loader with front kick broom made one pass through the test site; the resulting final cleared lane is shown in Figure 21.

Following the CTL with broom was the Tymco 600 vacuum truck. After an initial pass using both brooms and vacuum, the Tymco left medium-sized gravel behind, as shown in Figure 22.

After the final sweep/vacuum debris removal steps were completed, a LiDAR survey was conducted to measure change detection and performance of equipment.

Figure 21. Sweep mark from CTL 279D with front broom.

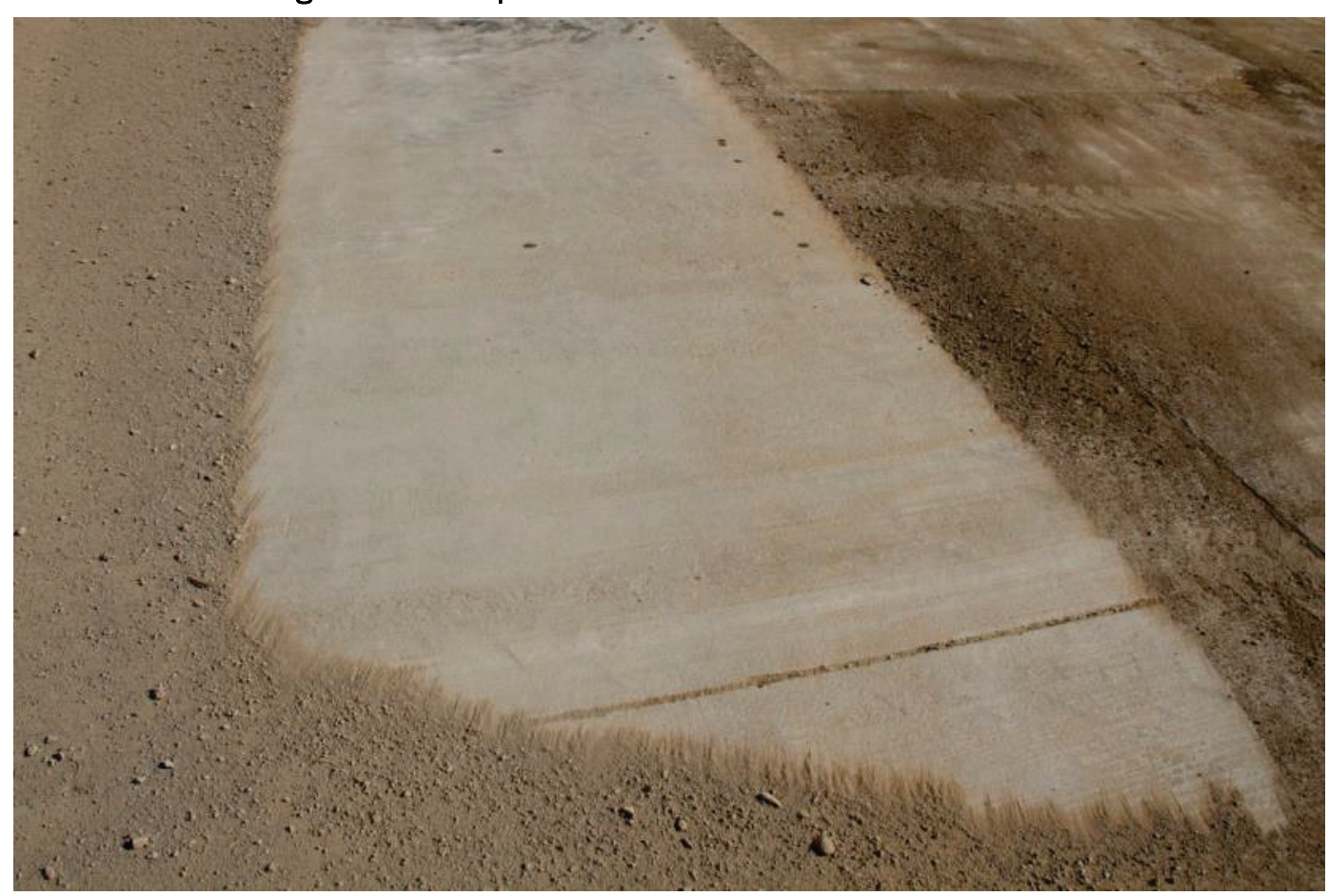


Figure 22. Tymco 600 vacuum/sweep; medium gravel left behind.

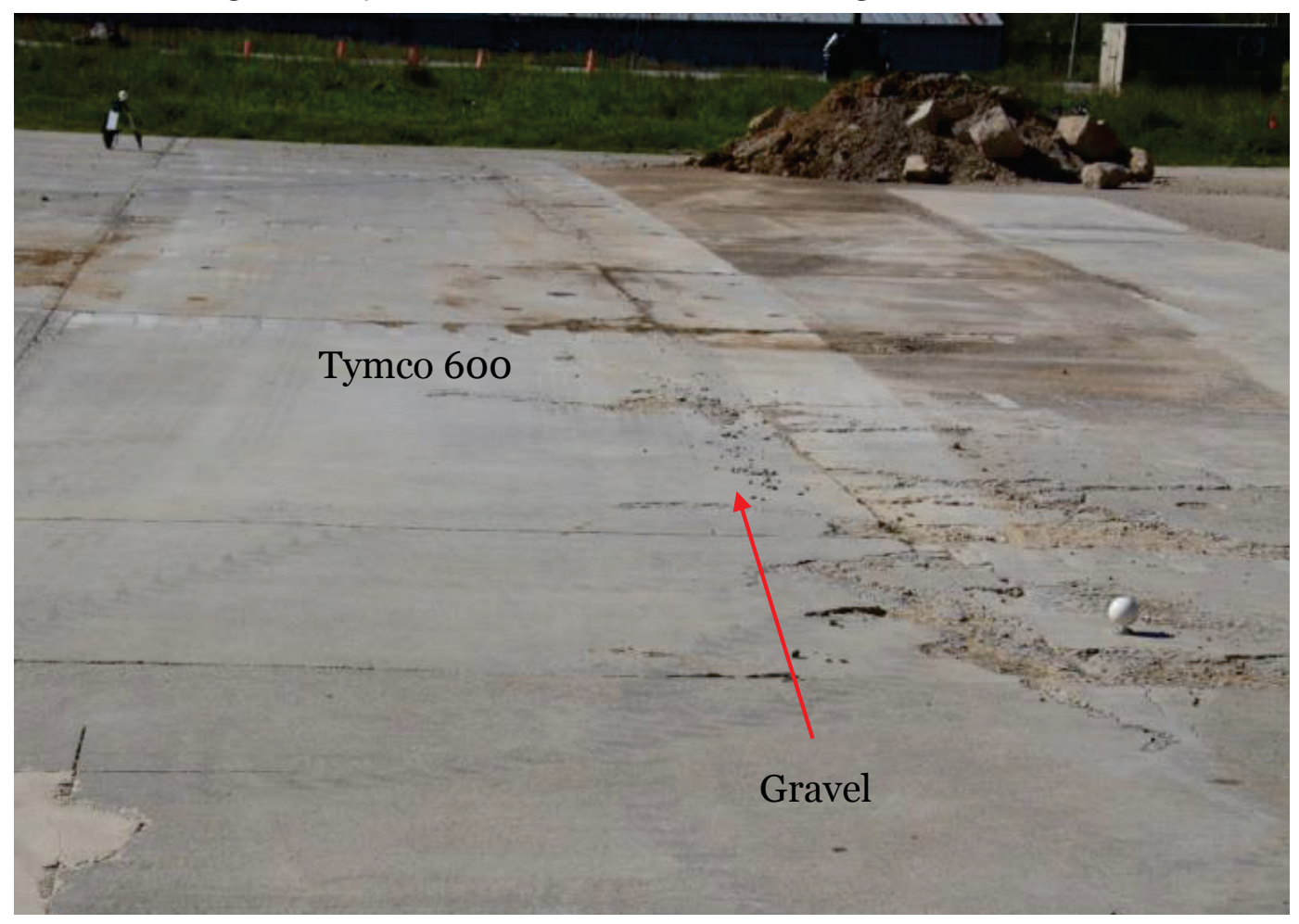

\subsection{Test 2}

Initial debris removal was next conducted with the CTL 279D with front bucket attachment (Figure 23). The time to clear the crater was 7:01 min. The CTL is also a baseline vehicle. The CTL is not currently deployed in the ADR kit, as it is coming online as next generation equipment. The final debris removal task evaluated the Tymco 600, FOD Boss 8 GF, and the compact track loader with broom and pan (Figure 24).

\subsection{Test 3}

The Ditch Witch SK 750 was evaluated for the initial debris removal task. The crater clear time was 32:20 min. The equipment demonstrated excellent maneuverability. The final debris clearance was initiated with the FOD Boss and the CTL 279 D Broom with pan (Figure 25). The CTL 279 D with broom (but without pan) has been procured, but not yet integrated into the ADR equipment package. This part of the test was conducted to see how well the pan worked. The operation with the pan was good, but the pan did not significantly improve its operation. 
Figure 23. Initial debris removal with CTL 279 D.

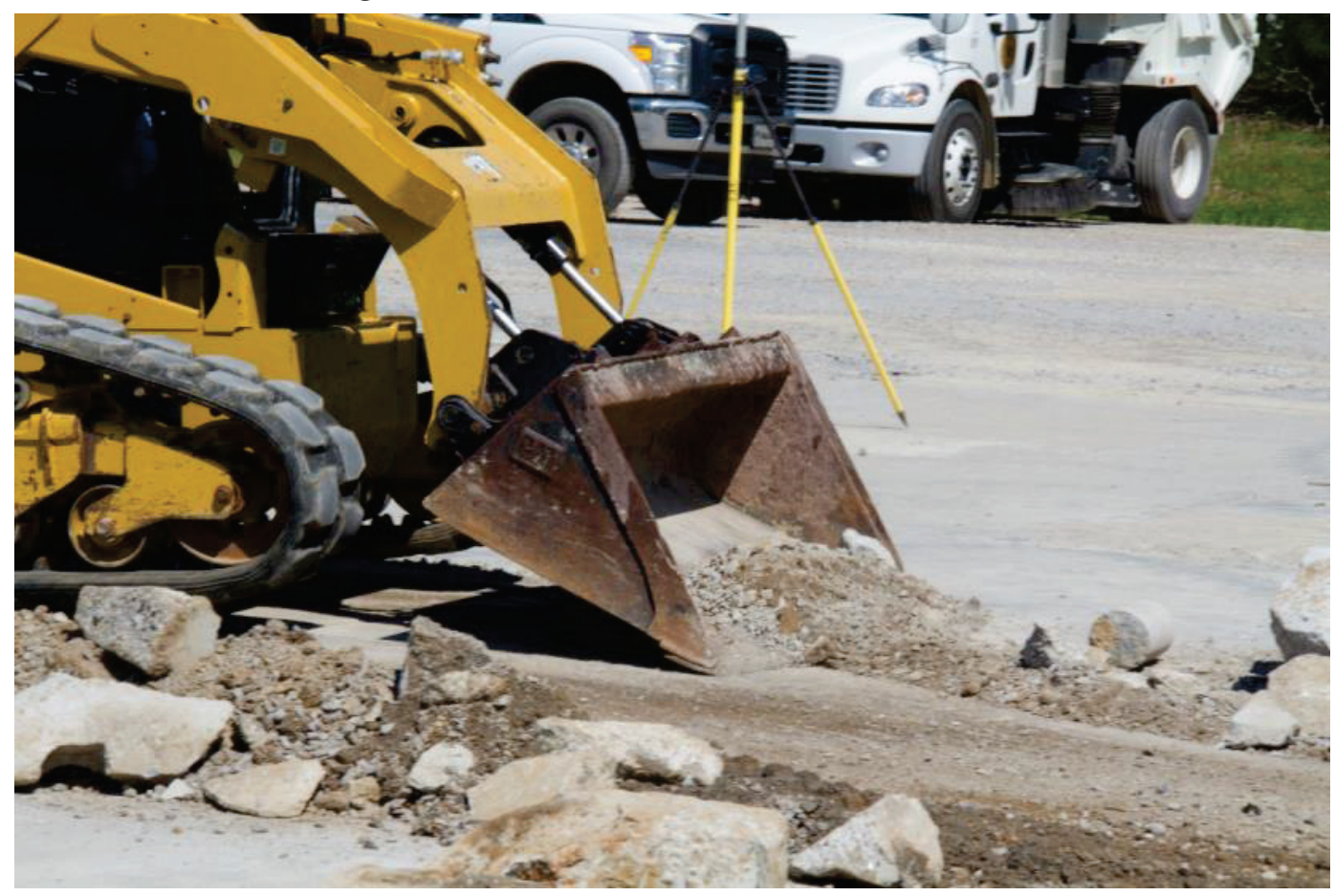

Figure 24. Passes from left to right: CTL Broom, FOD Boss, and Tymco.

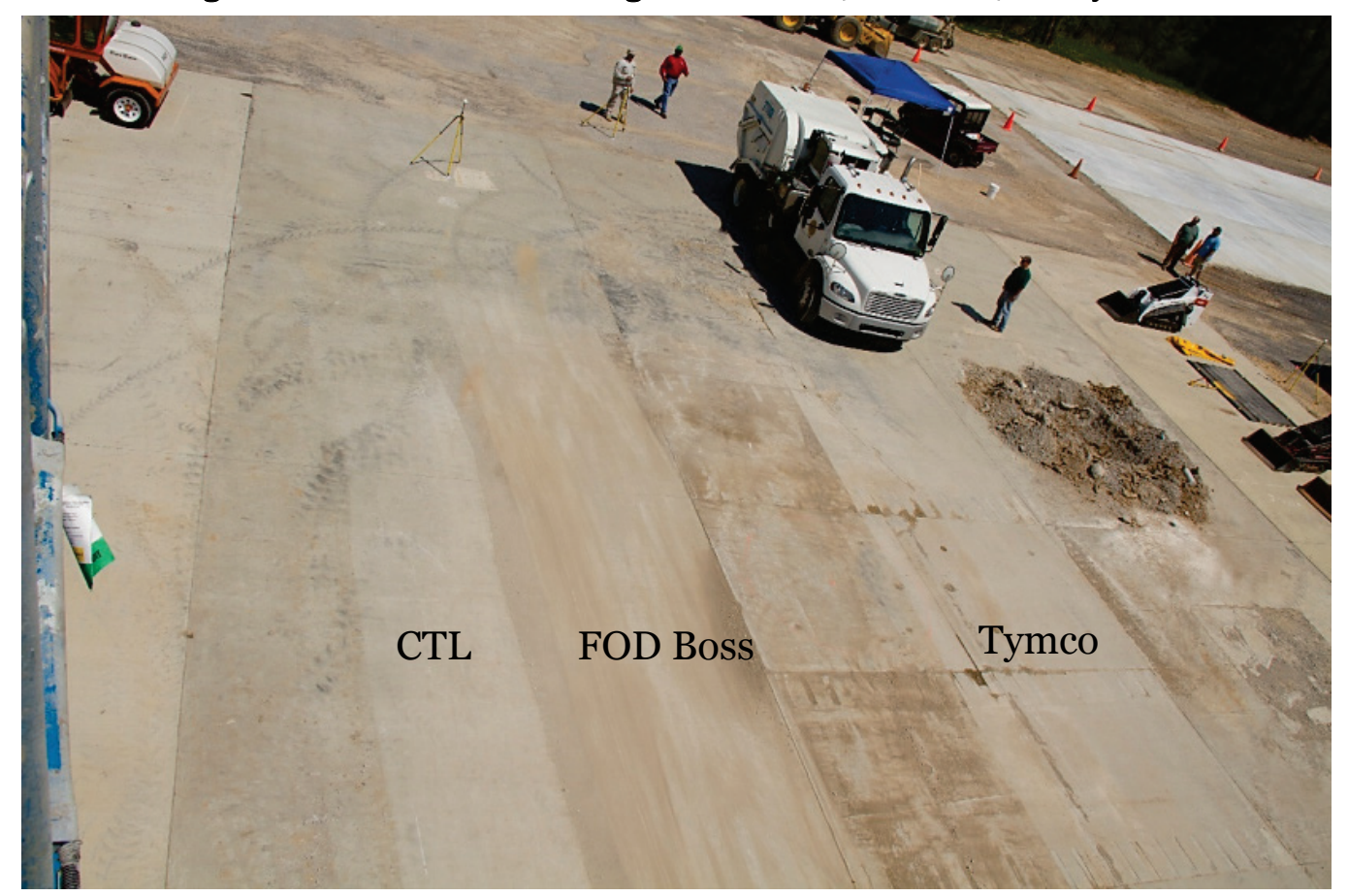


Figure 25. CTL Broom with pan.

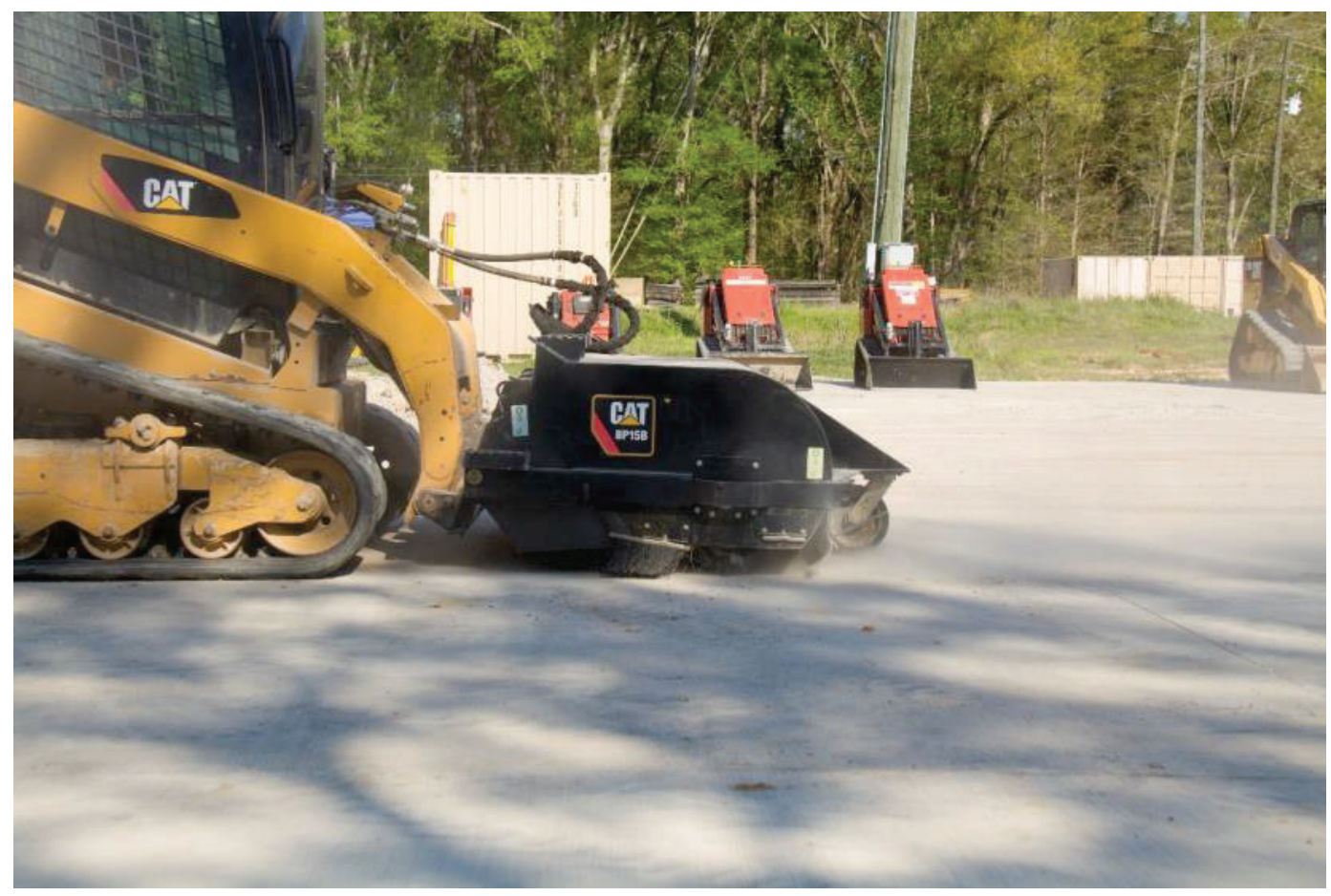

\subsection{Test 4}

This test was conducted only to evaluate potential final debris clearance equipment. In preparation, the initial debris removal was cleared with the CTL 279 D. The initial crater clear time was 9:17 min. The final debris removal evaluation consisted of testing the Tennant Sentinel, the Tennant 80o, and the Tennant S30. To evaluate the vacuum performance of the equipment, the vehicles did not engage their brushes (see Figure 26). The Tennant vacuums were able to pick up fines to medium gravel.

\section{$5.6 \quad$ Test 5}

As in test 4, the initial debris removal was implemented by the CTL 279 D. For this time trial, the crater clear time was 10:20 min. Final debris was executed by the Tennant S 30 and the Tennant "80o." During this test, the final components of debris equipment engaged their brushes. The Tennant $\mathrm{S} 30$ did not stir up dust during testing. The Tennant 800 created a small amount of dust. The performance is shown in comparing the initial condition in Figure 27 and the final cleared lanes in Figures 28 and 29. 
Figure 26. Tennant equipment with one pass and no brushes.

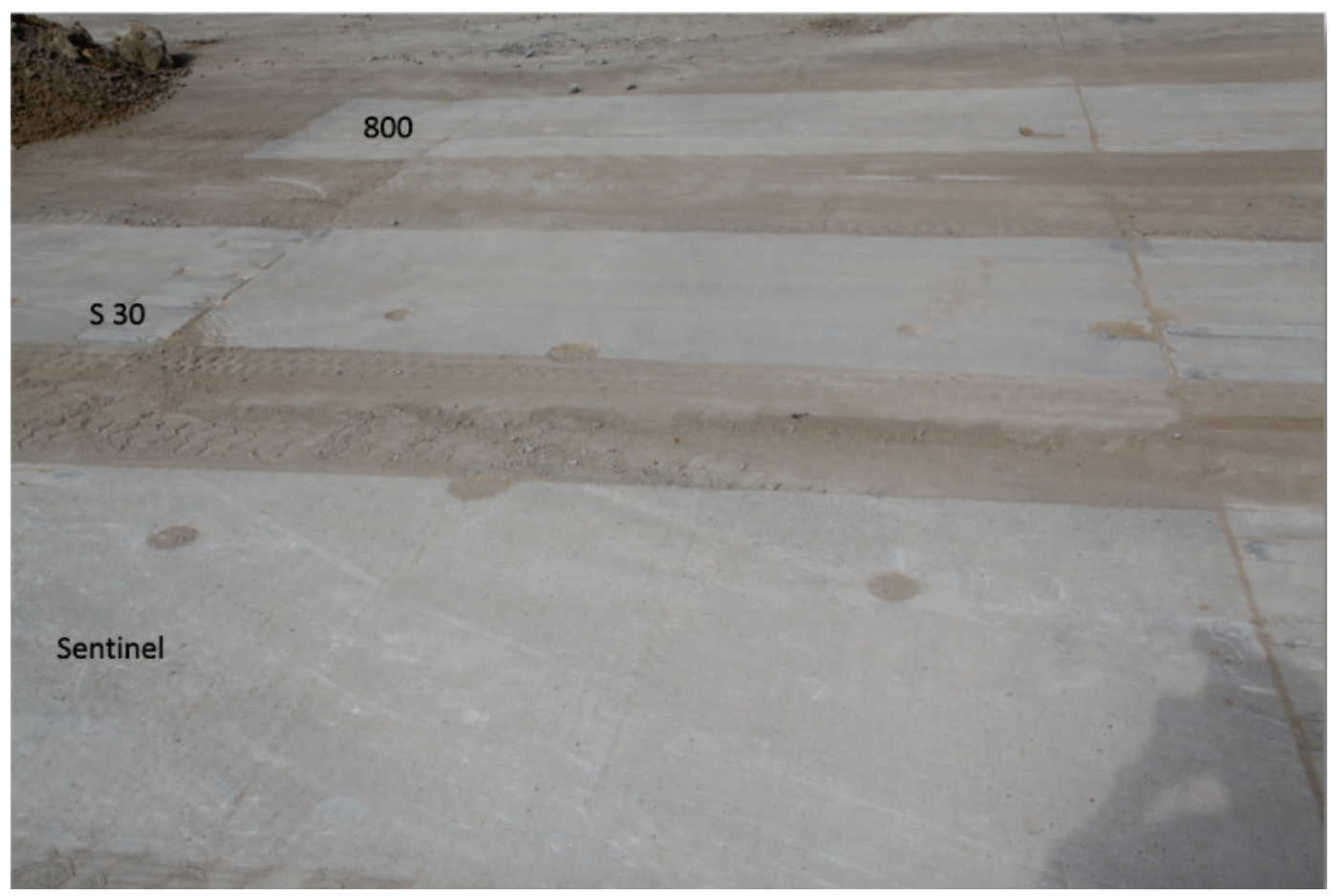

Figure 27. Flight line after initial debris removal and before vacuum/sweep.

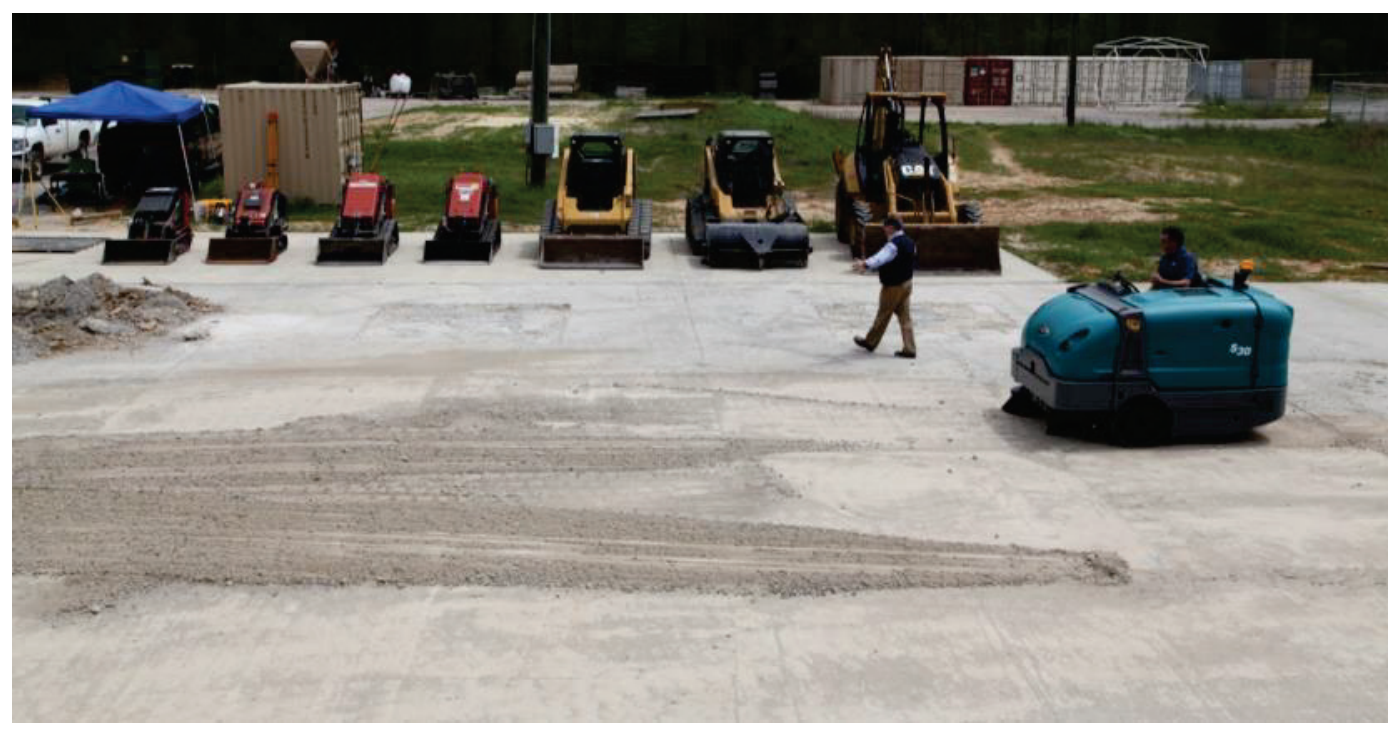


Figure 28. Tennant vacuum and brush activated in gravel.

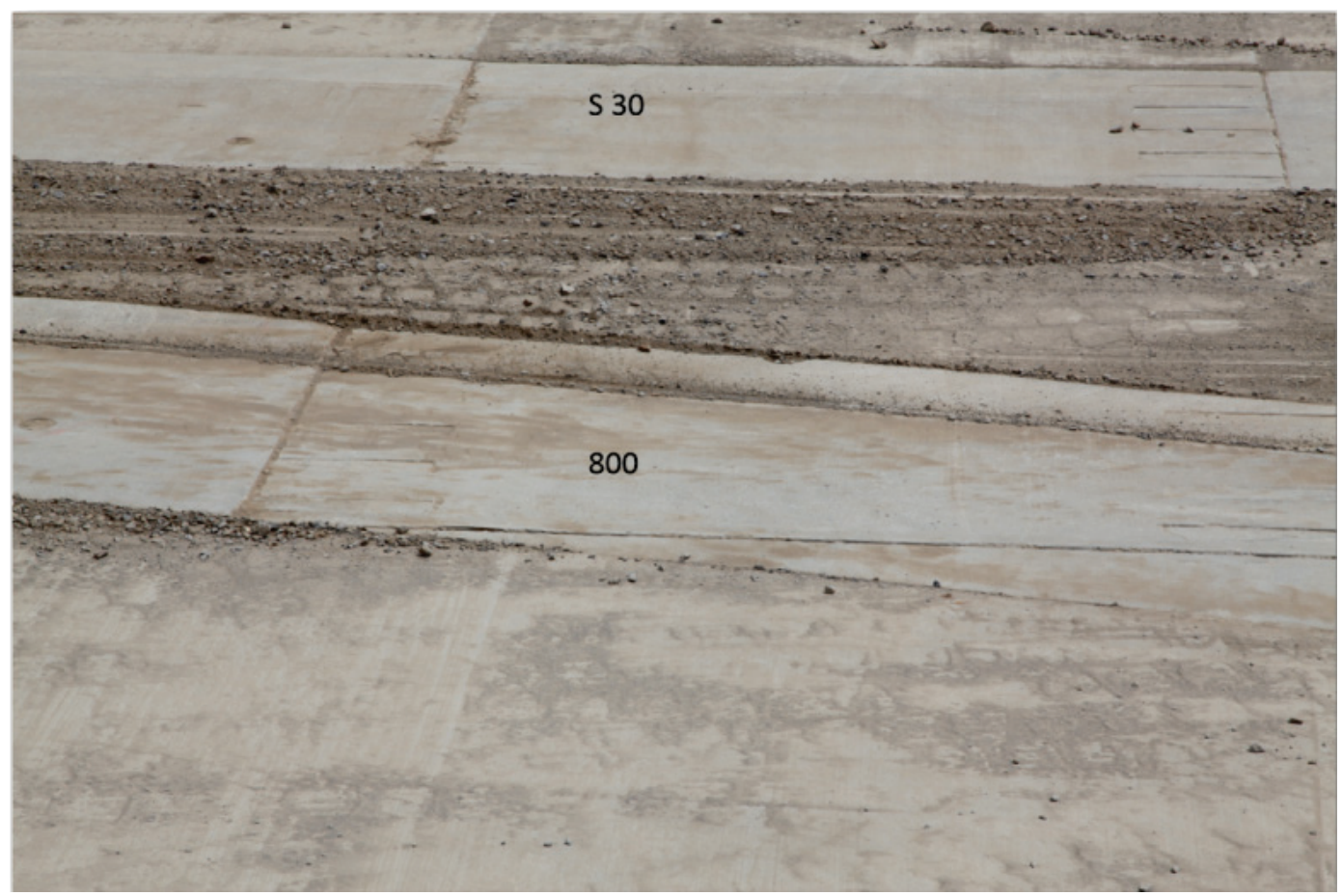

Figure 29. Final cleared lanes of Figure 28 at a different angle: 800 (right) and $\mathbf{S} 30$ (left).

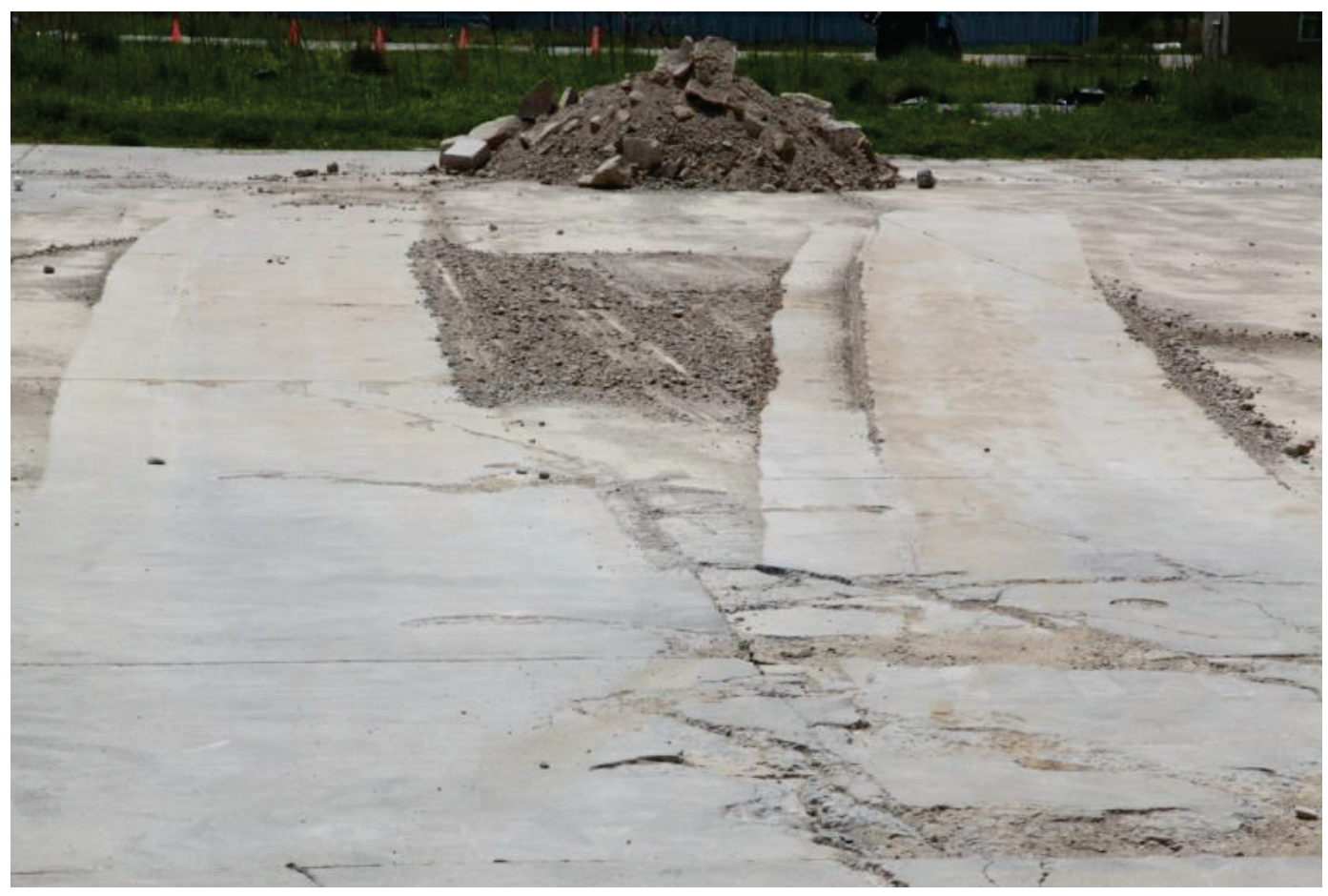




\subsection{Test 6}

This test of initial debris removal was executed with a mini track loader, which is significantly smaller equipment than the baseline and the next generation CTL. This test deployed the Bobcat MT 85 for timed debris removal. The crater clear time was 34:19 min. During the initial testing, it was observed that the bucket's width was equal to or slightly wider than the track's width (Figure 30). This caused debris to run under the track and lift the equipment, potentially throwing the operator. The final debris removal was employed by the CR 350 manufactured by Broce. For the purpose of data collection with LiDAR, no water was used for dust control. Two passes were conducted with the Broce broom. First, the Broce made a sweeping pass with the broom straight; and, second, the pass was made with the broom angled (Figure 31).

\subsection{Test 7}

For this test, an 8-ft crater was constructed. The initial debris removal test was executed by two Ditch Witch SK 750 mini track loaders and two operators. The crater clear time was 7:49 min. The ADR push-feed method was employed. The test showed that with multiple mini track loaders, the time improved significantly.

Figure 30. View from rear of Bobcat MT 85 showing width of bucket equal to track width.

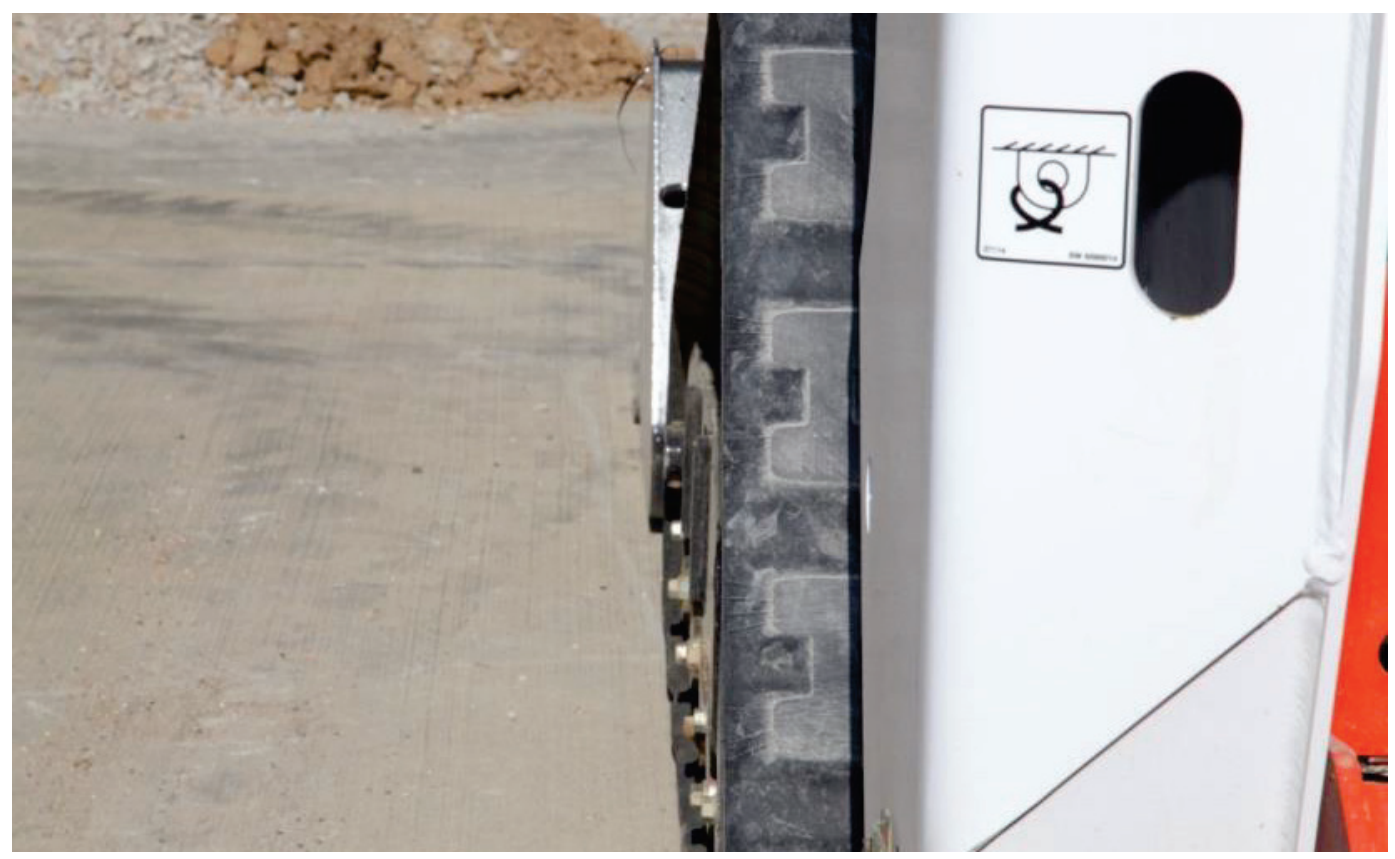


Figure 31. Broce broom passes: straight (left) and angled (right).

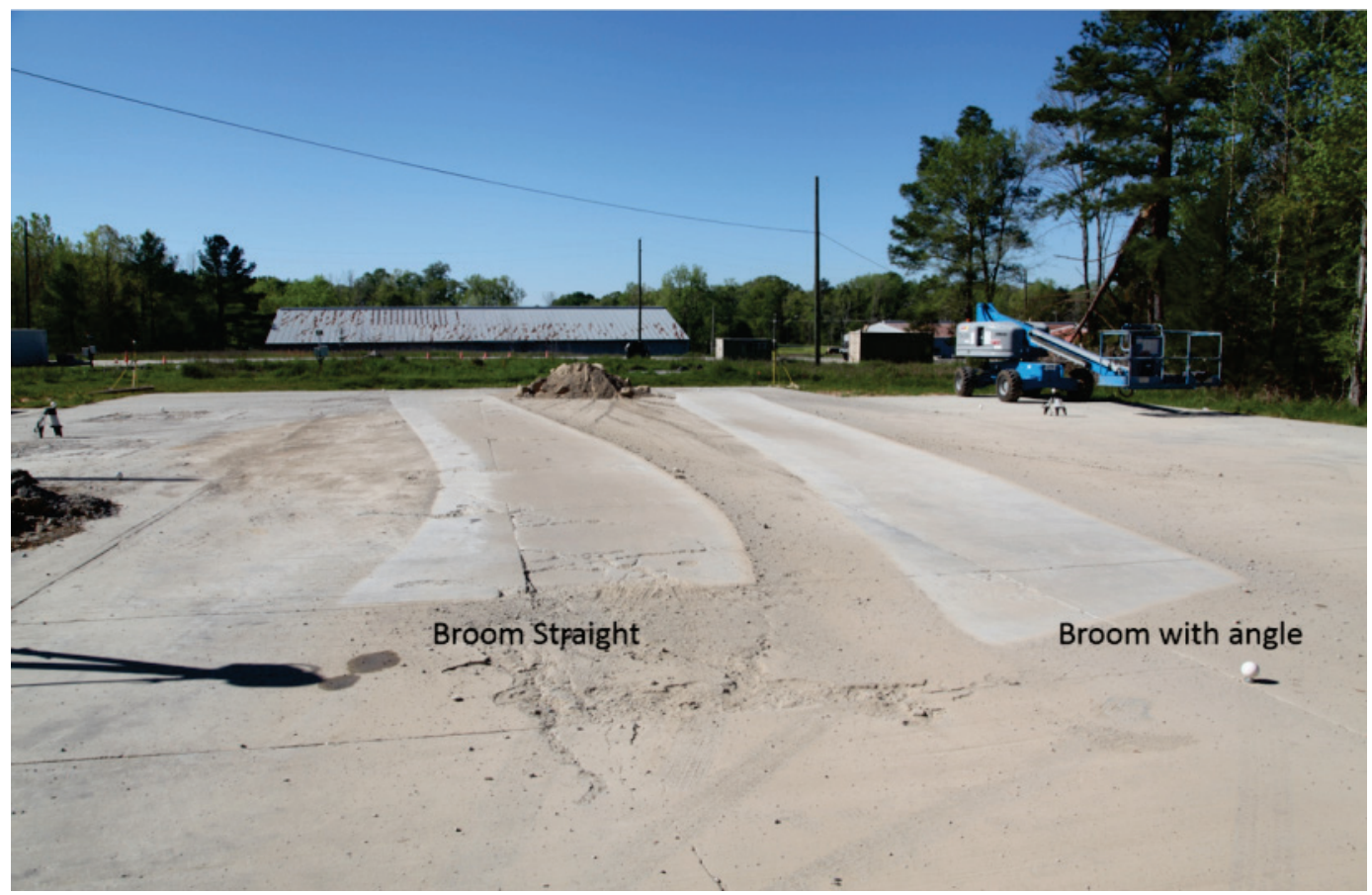

\subsection{Summary of test results}

A summary of the evaluation tests is shown in Figure 32. The equipment that performed the best, based on potentially leaner, lighter next generation equipment for rapid mobilization, was the Ditch Witch SK 750. It was the easiest to control and worked well when initially removing debris. It handled better and was faster than the MT 85 Bobcat. The SK 750 had a bucket wider than the track, which prevented debris spilling from the side of the bucket and going under the tracks. Tracking over this trailing debris pile caused control issues, reducing scraping effectiveness. Therefore, it was noticed that taking smaller bites of debris when performing initial clearance helped with spillage of material from the sides and might be important for the effective operation of the smaller equipment. For initial debris clearance, use of the smaller equipment increased the time that was expected for smaller capacity equipment versus the existing baseline equipment. However, with multiple smaller next generation, leaner, lighter equipment, depending on the threat, an ADR mission can be completed. The TORO Dingo 525 was also evaluated, and it was soon discovered that it was too small and underpowered and not suited for the initial debris task. Initial tests concluded that the Ditch Witch SK 750 produced more speed than the Bobcat MT 85. Grades for the performance for final debris are (1) best performance, (2) acceptable performance, and (3) unacceptable performance - not recommended. 
Figure 32. Debris initial clearing equipment gross weight (red) and time to clear crater (blue) summary comparison.

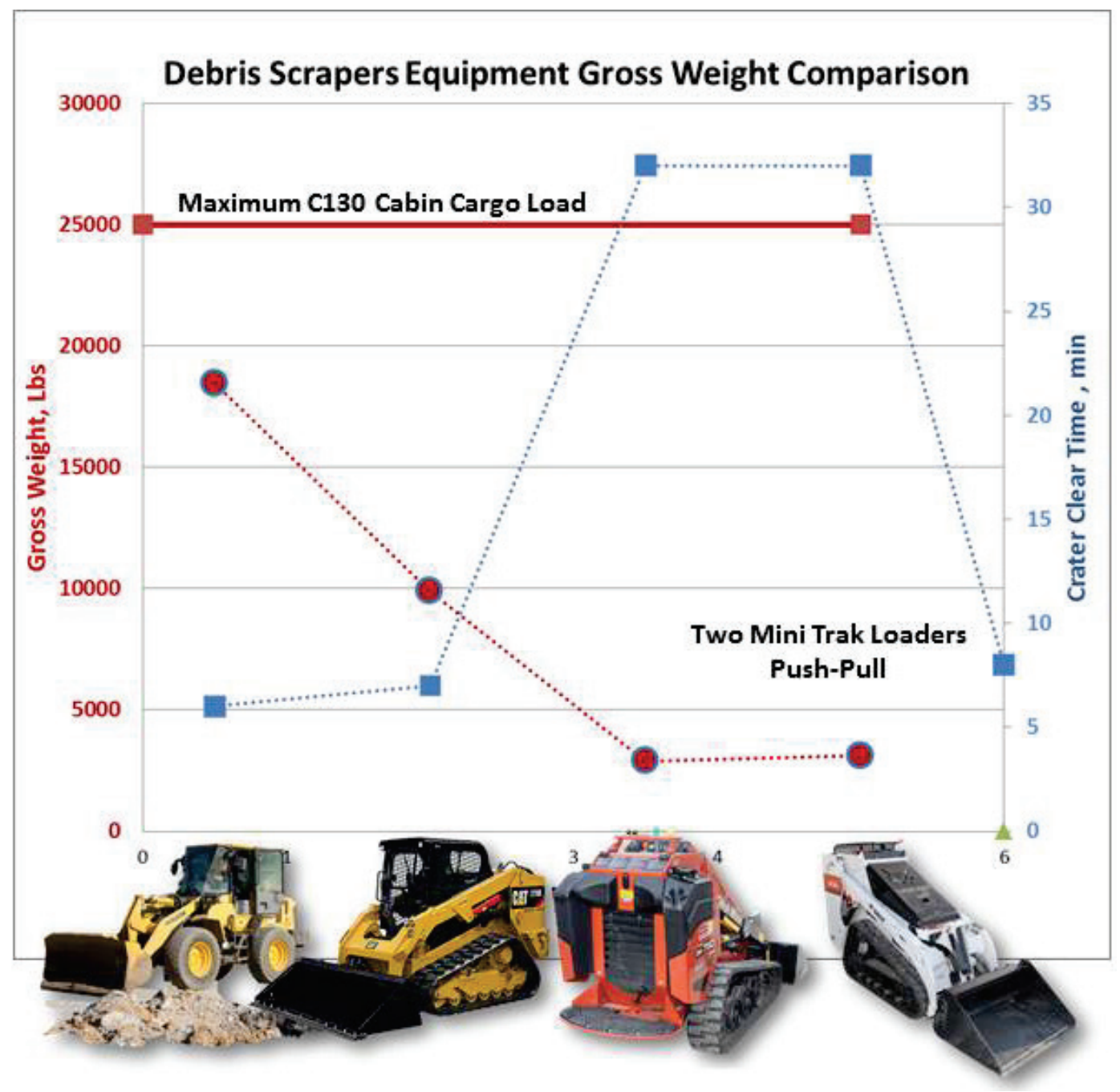

A summary plot of equipment gross weight and time to conduct the initial clear crater task is shown in Figure 32. This shows there is considerable savings in logistical effort in transporting the equipment from the front end loader to the CTL track loader and further significant reduction in the mini track loaders. The penalty in clearing time is also plotted. 


\section{FOD Boss Evaluation}

\subsection{Background}

An evaluation was conducted on a foreign object debris (FOD) removal device. This equipment is novel in that it is a simple, small, portable device that rakes FOD debris and catches it in its pockets, basically a passive sweeper and dustpan. This equipment is unique in its size and cost compared to a mechanical broom or vacuum. The deployed sweep width is 96 in., and the weight is $65 \mathrm{lb}$ with case. The FOD Boss 8 (Figure 33) was deployed to John Bell Williams Airport, Raymond, MS. The aprons are constructed of both concrete and asphalt. Tests were conducted to see how well the FOD Boss collected different types of materials. A real-world scenario was conducted at a construction site to see how well the device picked up debris from airport construction on taxiways.

Figure 33. FOD Boss 8 ground force.

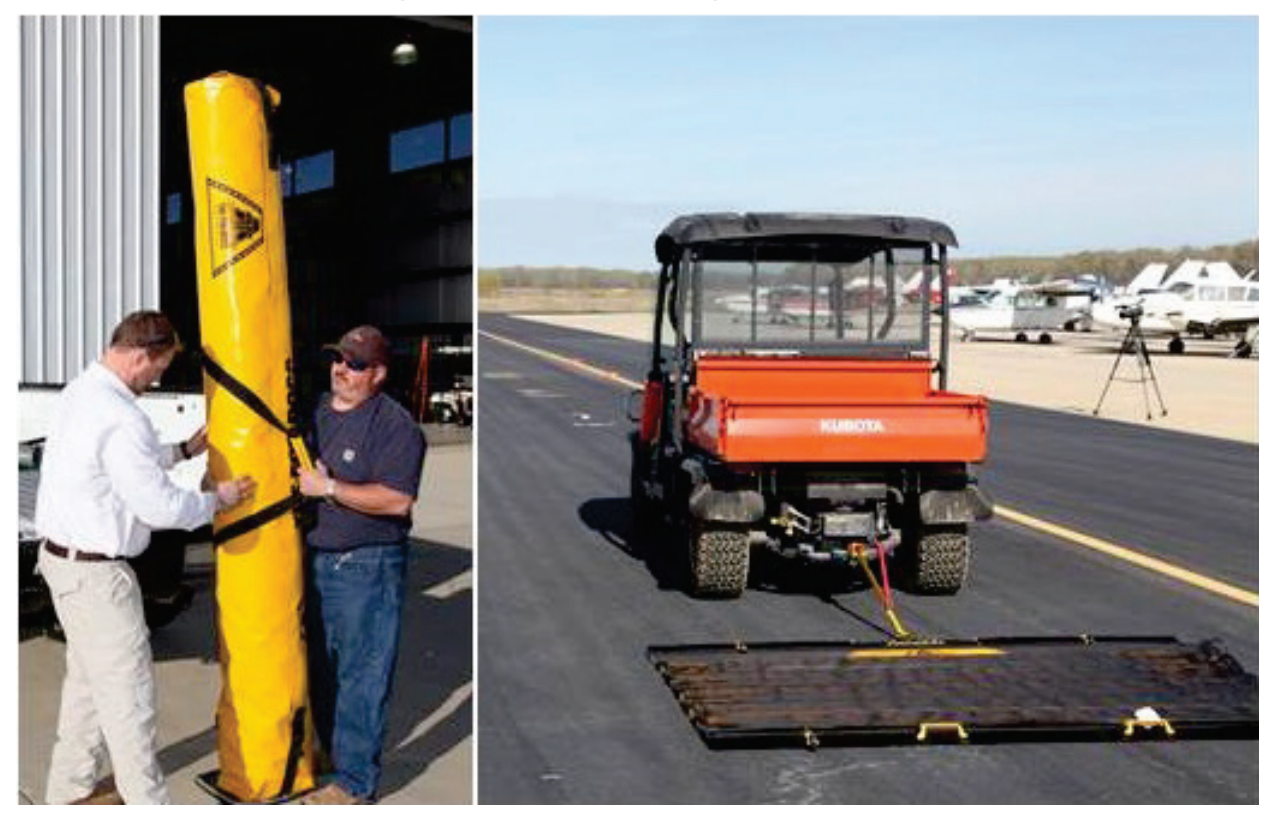

Items that were used in the testing consisted of 1-1/4-in. bolts, light chain, copper shillings, wire rope, steel $\mathrm{C}$ channel, stainless steel pins, square bar, 2-1/2-in. pins, small aluminum stock pieces, 1-3/4-in. bolts, 2-in. bolts, 3-in. bolts, 1-1/2-in. bolts, 9/16-in. bolts, random nuts, washers, lock washers, 12-gauge coated wire, 10-gauge wire, 50-caliber casings, 556-caliber casings, 38-caliber casings, 243-caliber casings, 40/70 sand, $6 / 9$ sand, and concrete sand (Figure 34). 
Figure 34. Foreign object debris used in FOD Boss tests.

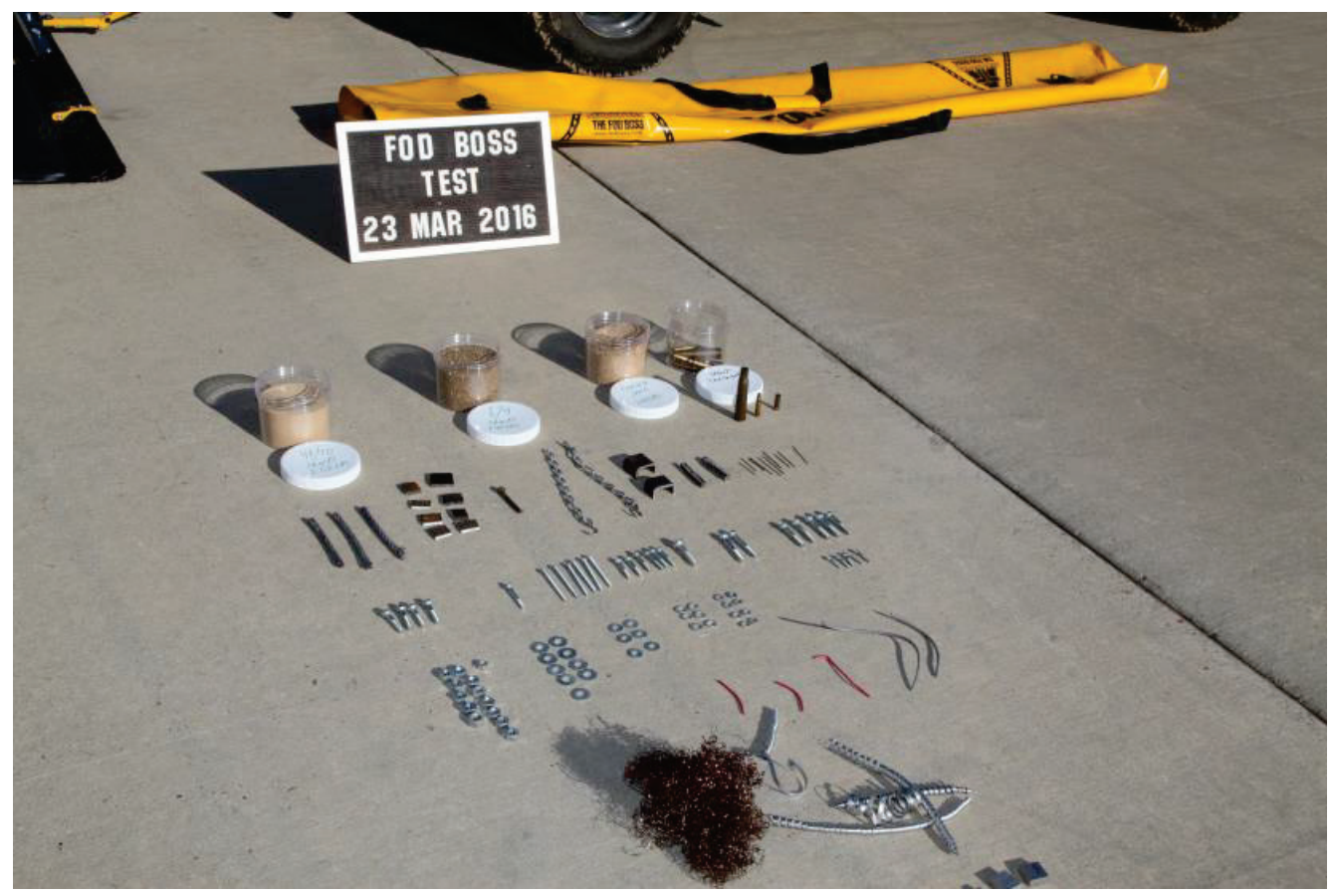

\section{$6.2 \quad$ FB Test 1}

Markers were placed at 20- $\mathrm{ft}$ intervals along the apron. The three types of sand were poured out at the markers, and electrical wire was placed at each marker. The FOD Boss was pulled at a slow rate of speed of around $5 \mathrm{mph}$. The manufacturer recommends speeds between $4 \mathrm{mph}$ to $25 \mathrm{mph}$. Pass 1 picked up most of the sand and removed both wires. Pass 2 removed additional sand and forced some sand into the surface voids (Figure 35) (filling the surface voids between the material aggregate). The subsurface sand was agitated by the leading edge of the FOD Boss and swept up, causing the aft blades to catch sand debris. Additional debris that was not test material was captured (Figure 36).

\subsection{FB Test 2}

Large gravel was placed at $\mathrm{oft}$ (Figure 37), wire rope was placed at $20 \mathrm{ft}$ (Figure 38), casings were placed at $40 \mathrm{ft}$ (Figure 39), and random nuts, bolts, chain, c-channel, washers, and aluminum chunks were placed at $60 \mathrm{ft}$ (Figure 40). The FOD Boss was again pulled one pass at a slow rate of speed of approximately $5 \mathrm{mph}$ (Figure 41) and picked up all but two pieces of large gravel. Some gravel was agitated and thrown on top of the FOD Boss. 
Figure 35 . Sand debris subsurface in voids between aggregate.

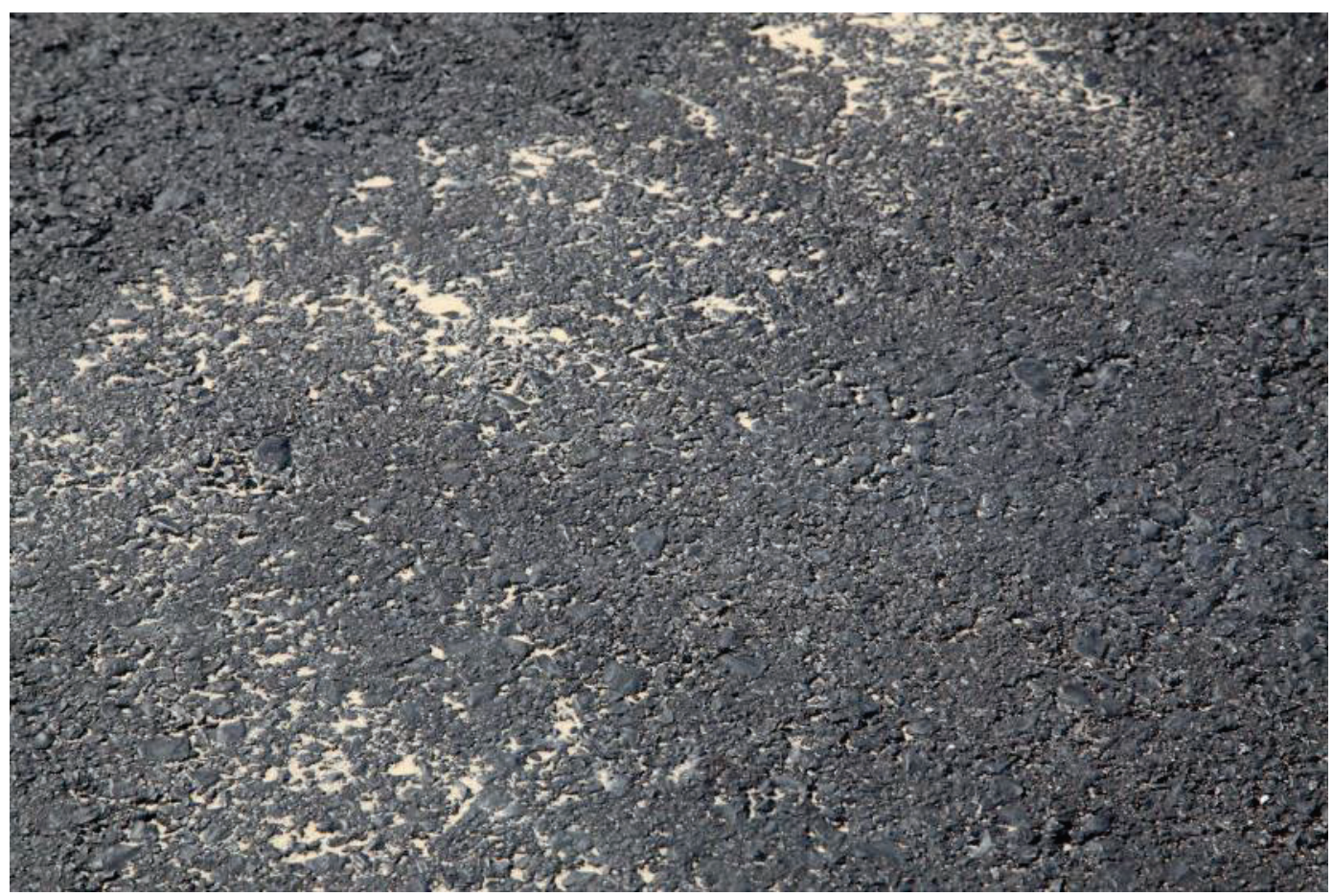

Figure 36. Results from test 1.

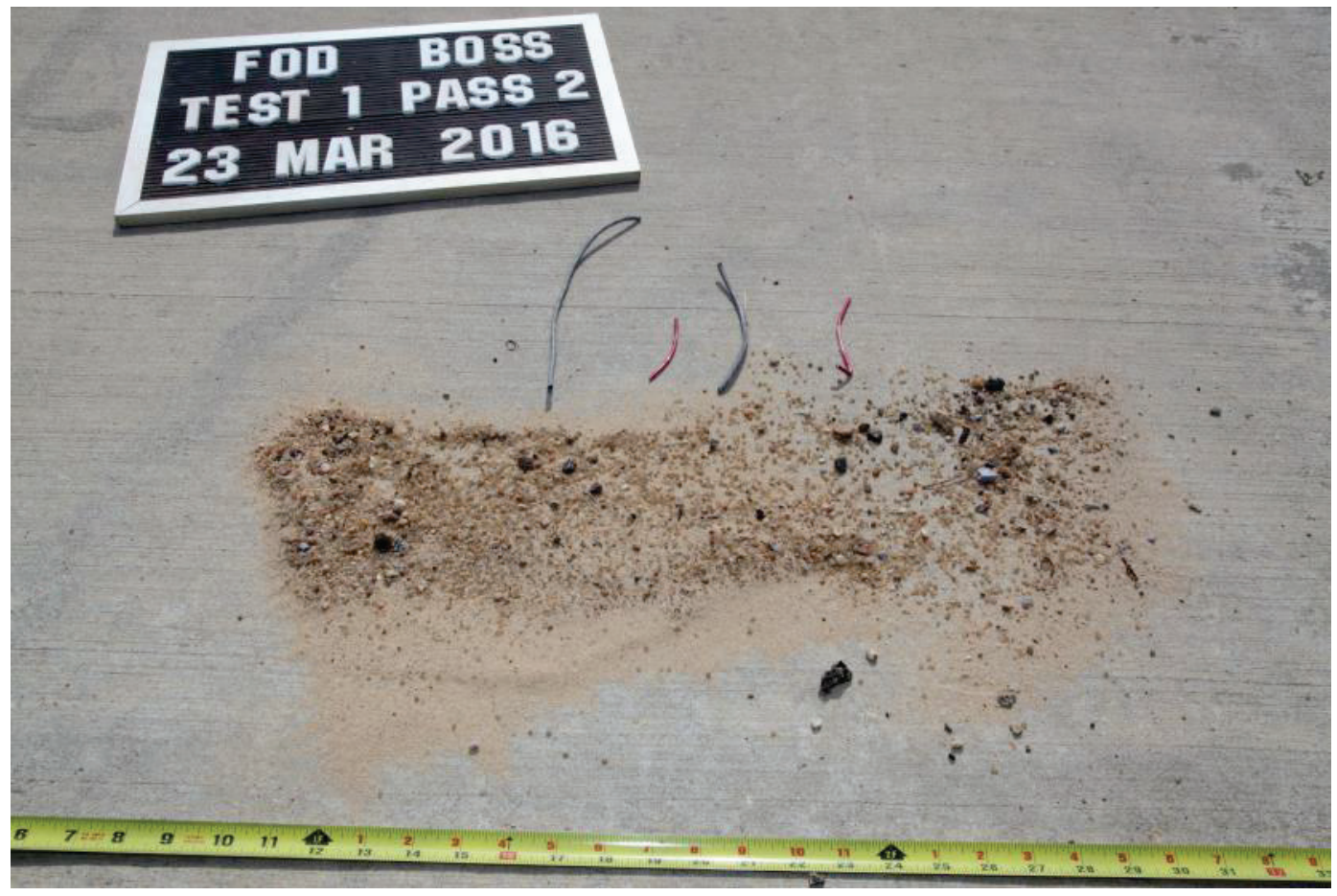


Figure 37. Large gravel placed at 0-ft marker.

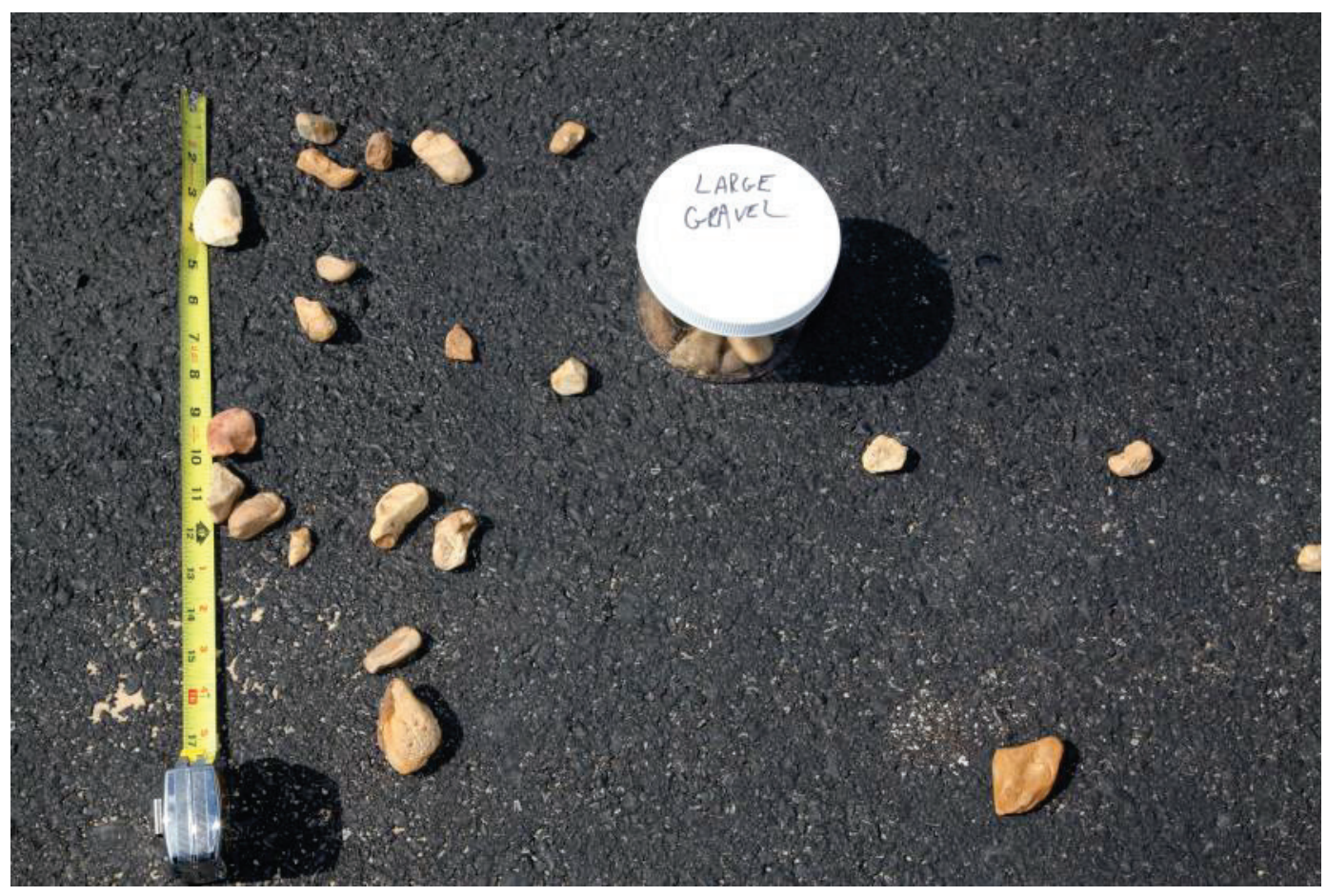

Figure 38 . Wire rope placed at the 20 -ft marker.

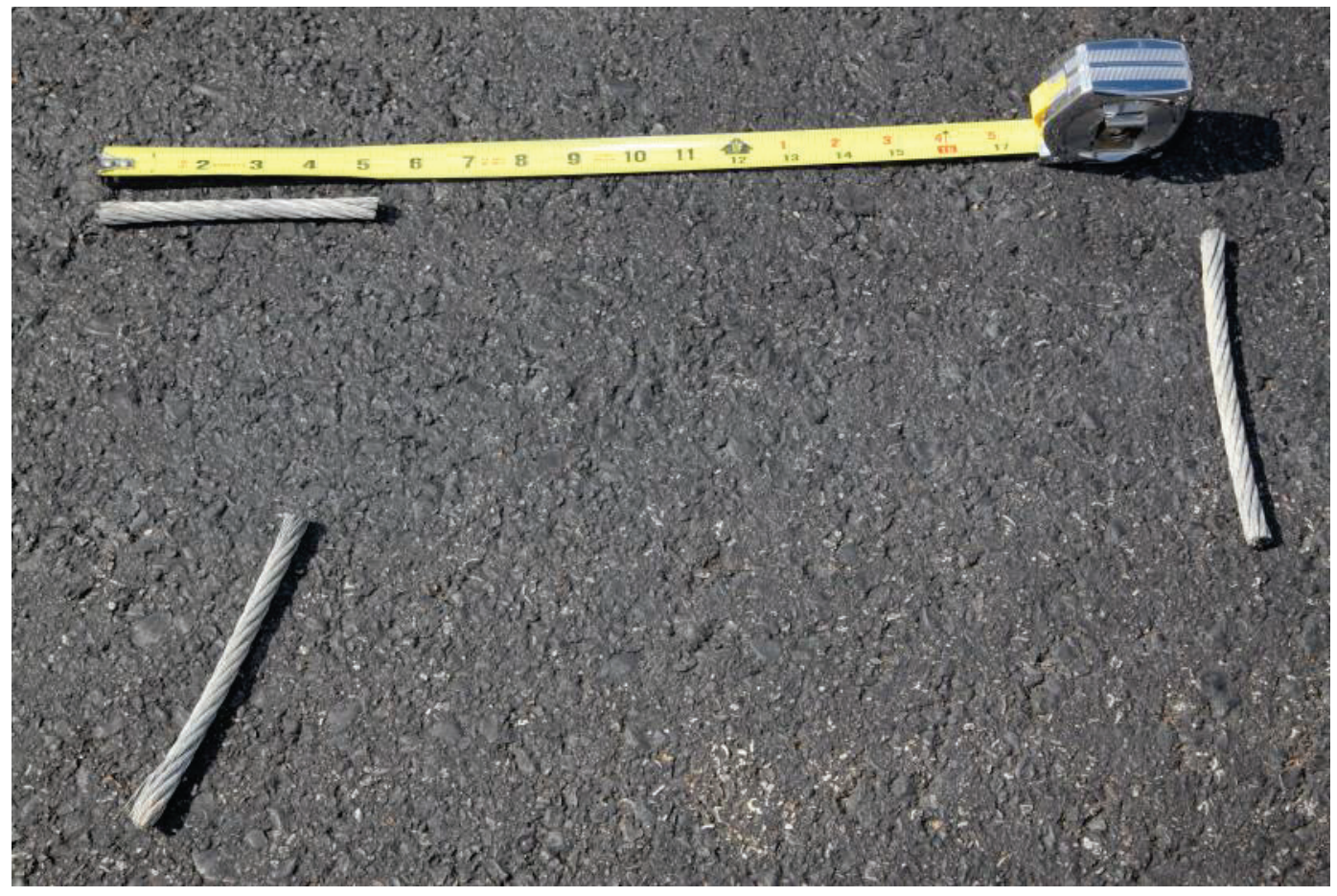


Figure 39. Ammunition casings placed at 40 -ft marker.

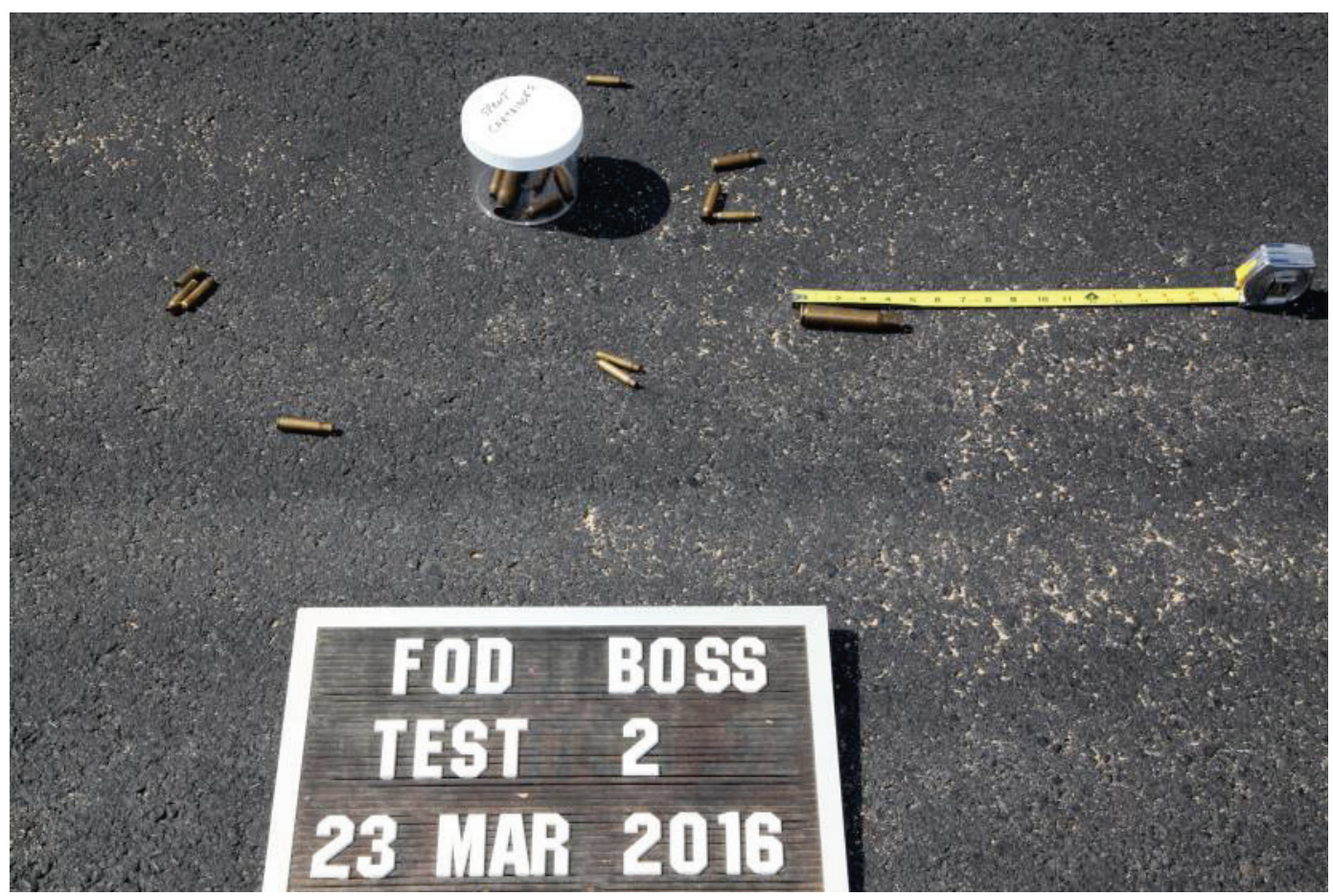

Figure 40. Random nuts, bolts, washers, chain, and metal placed at 60-ft marker.

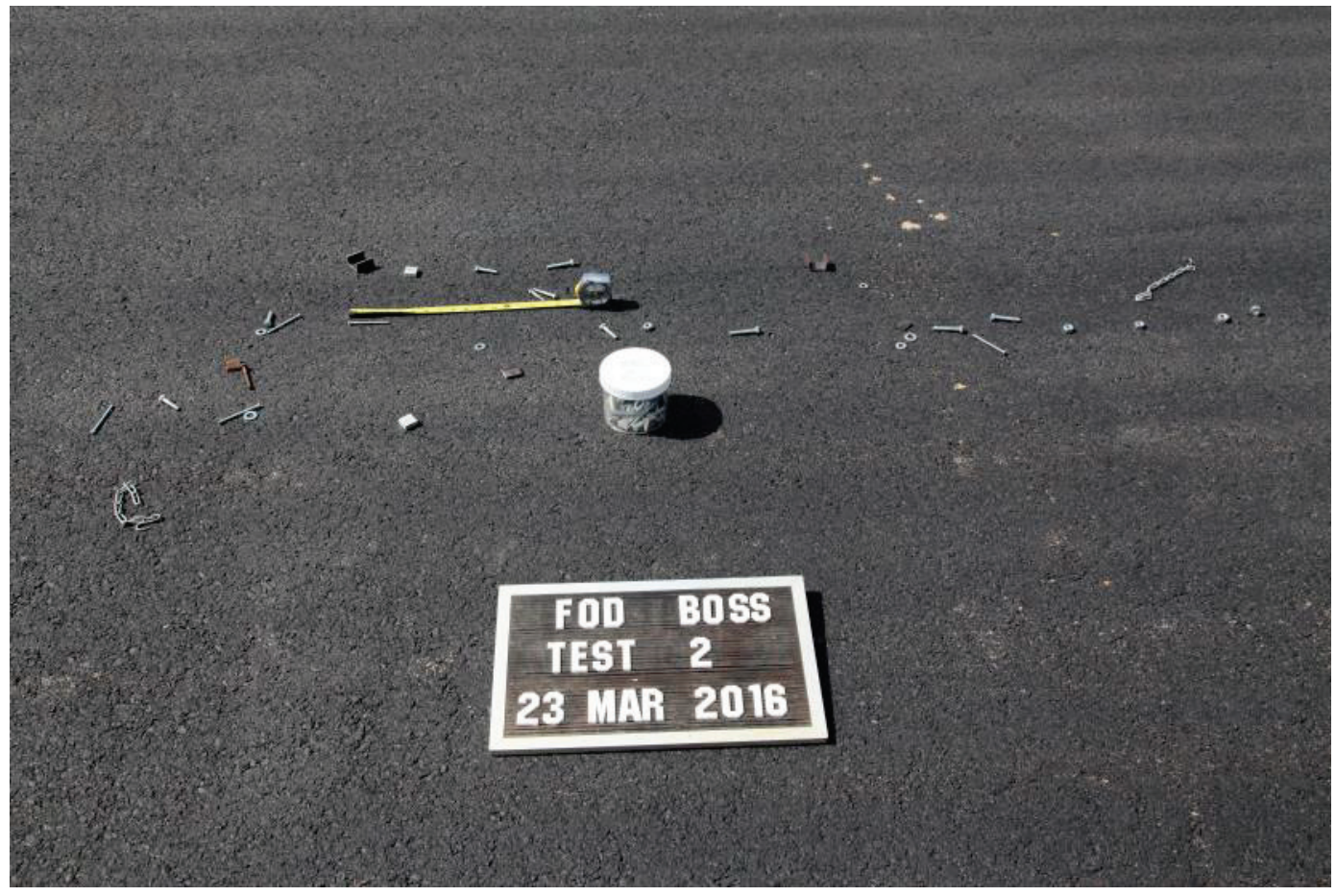


Figure 41. Results of one pass at slow speed with multiple types of FOD (Test 2).

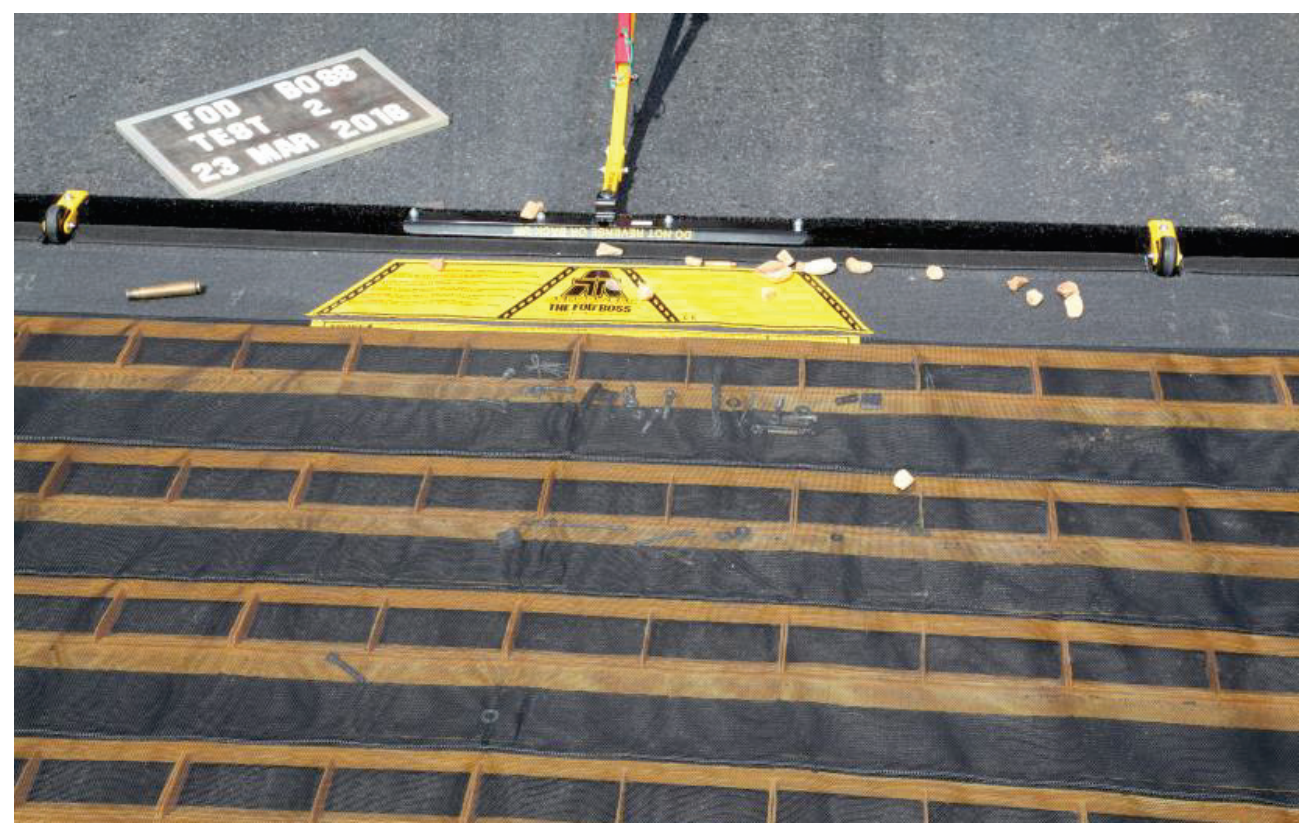

One length of wire rope was collected, leaving two other pieces. All casings were collected along with all nuts, bolts, and chain. One piece of c-channel was moved and partially wedged under the leading edge of FOD Boss (it did not get trapped in the pocket, but was caught and dragged along with the device).

\subsection{FB Test 3}

Construction was occurring on one of the taxiways (Figure 42), and heavy equipment was present. A real-world scenario was established, and the FOD Boss was tested to see how well it performed in collecting debris from the construction site. The FOD Boss was deployed at speeds of 5 to $25 \mathrm{mph}$ in the construction zone on the taxiway and apron for 8:44 min. Results of the construction zone tests are seen in Figure 43.

\subsection{Test results, evaluation, and conclusion}

The FOD Boss 8 performed well. If the first set of blades did not collect debris, usually the aft ones were successful. Deployment and setup was simple. The device also can be deployed as a towed array of multiple mats, allowing it to cover a greater surface area. The FOD Boss performed well when deployed at multiple speeds with various types of FOD. In its carry bag, the FOD Boss is $8 \mathrm{ft}$ long, $12 \mathrm{in}$. wide, and $10 \mathrm{in}$. high and weighs $65 \mathrm{lb}$. 
Figure 42. Construction zone at airport.

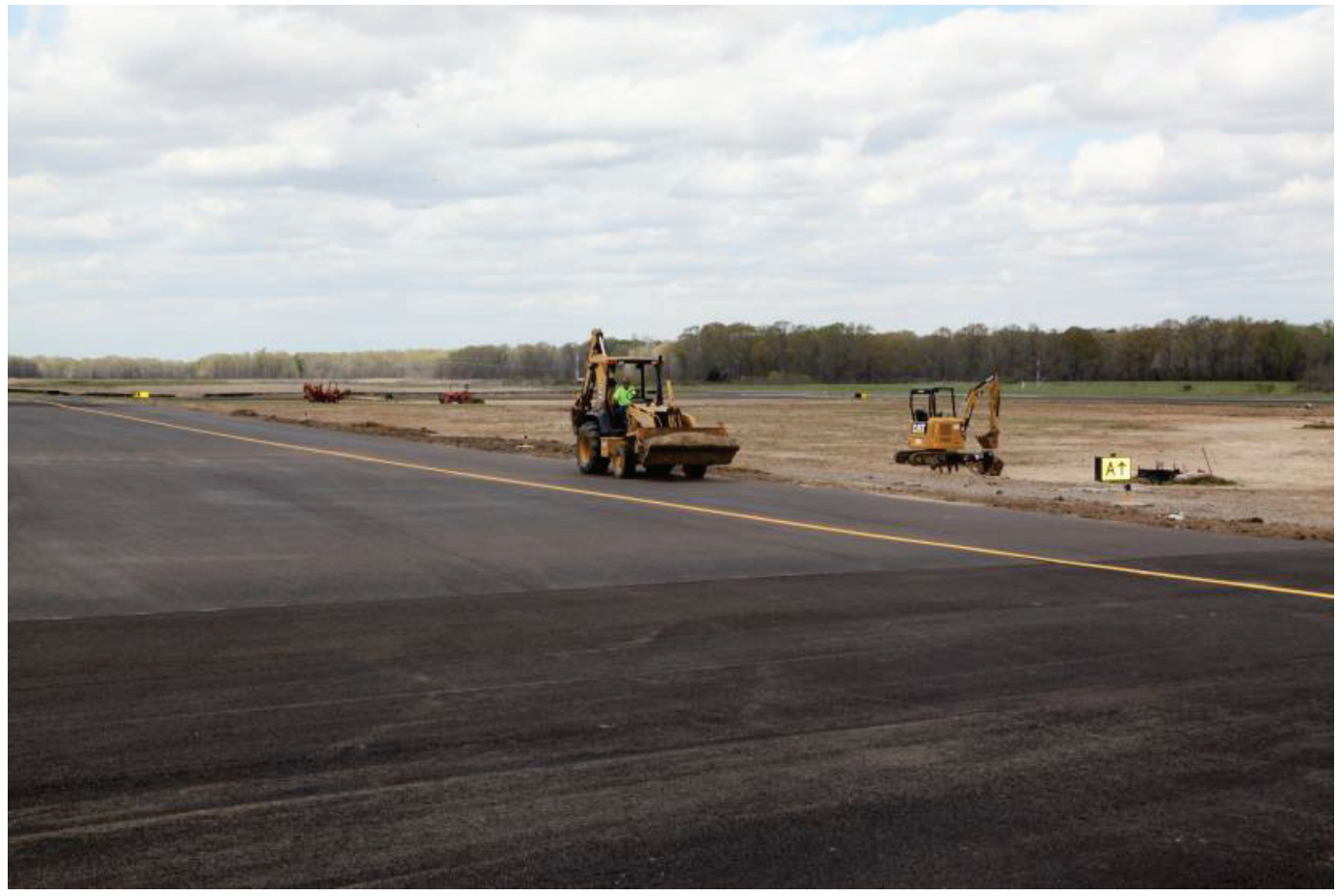

Figure 43. Debris collected after construction zone test.

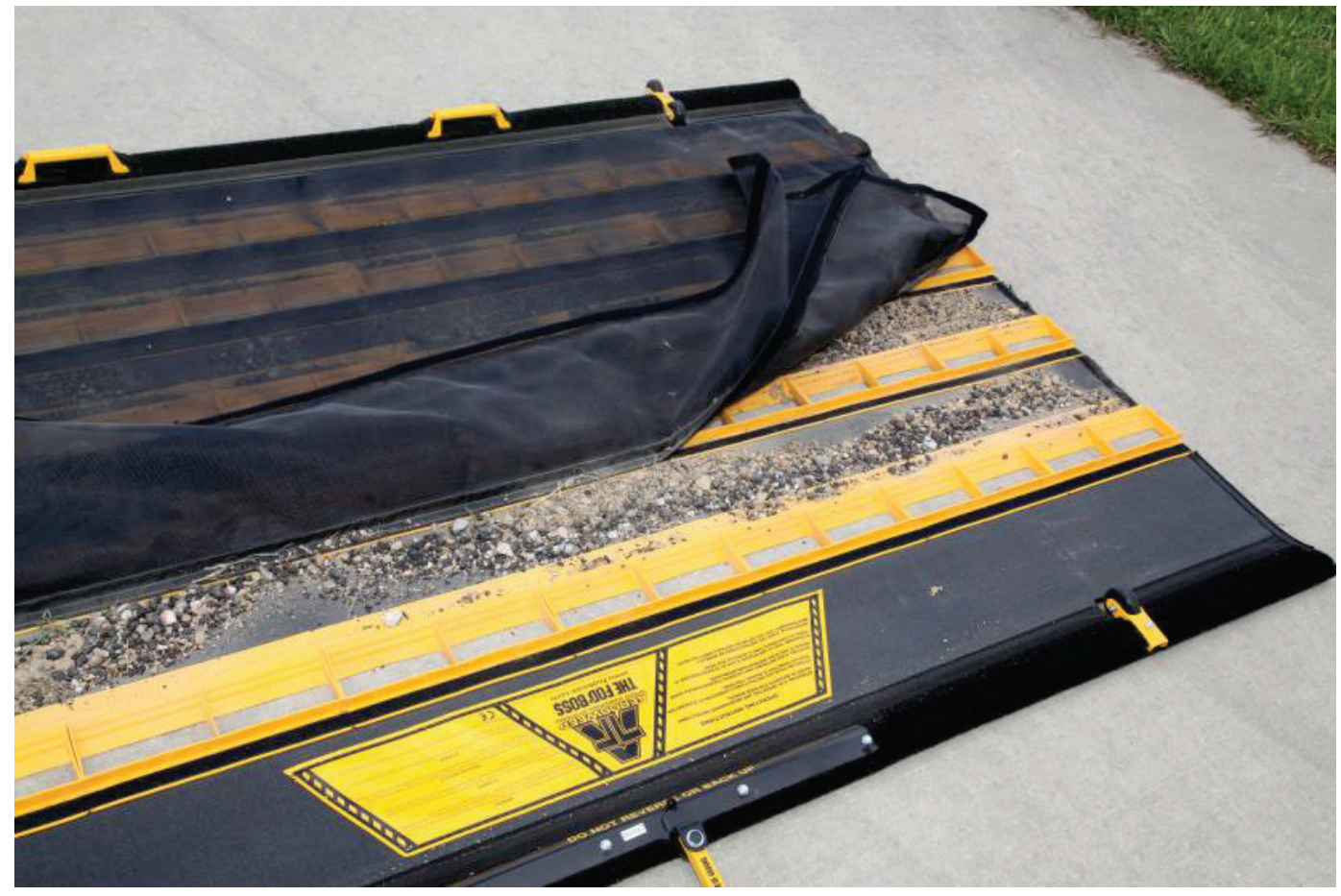




\section{Conclusions and Recommendations}

Research was conducted at ERDC in Vicksburg, MS, to evaluate leaner, lighter equipment for deployable debris removal post missile strike for airfield damage repair. Market research was conducted to identify commercial technology that could be adopted and adapted to meet next generation requirements of debris removal equipment with a reduced logistical footprint and performance characteristics relevant to the Airfield Damage Repair mission. Potential candidate equipment from the market survey was field evaluated, and the results were compared along with results of existing baseline equipment and the next generation compact loader. The mini track loaders were identified as a task-capable class of equipment that provides an option for easier mobilization and reduced logistical footprints with capabilities to perform typical tasks associated with an ADR scenario involving debris removal. Selected mini track loaders were evaluated to verify how well they were able to clear an 8 -ftdiam crater in a specified amount of time. The following sections present the findings and recommendations resulting from the evaluation of these leaner and lighter mini track loaders.

\subsection{Market surveys of potential of next generation equipment mini track loaders}

- Results of the market survey indicate a minimum rated capacity of 3,00o lb is required to perform all ADR tasks

- Results of the market survey of currently available mini track loaders indicate lower capacity equipment solutions are easily capable of air transport via $\mathrm{C}-130$ and can perform all ADR tasks.

- Results of the market survey of currently available sweepers/vacuums indicate lower capacity equipment solutions are capable of air transport via $\mathrm{C}-130$.

- Results of weights of equipment investigated were found to be substantially less than current ADR equipment.

\subsection{Recommendations}

- Based on the field evaluation exercises, the following minimum equipment characteristics are recommended for the performance of all identified ADR tasks: 
- Minimum engine displacement of $55 \mathrm{in}^{3}$,

- Minimum weight of $3,200 \mathrm{lb}$,

- Minimum speed of $4 \mathrm{mph}$, and

- Minimum hydraulic of 12 GPM.

- Based on the field validation exercises, it was found that having a bucket wider than the track helped eliminate material from getting under the tracks and causing a rough ride for the operator.

- Field evaluations found that the control system on the SK 750 Ditch Witch was easier to manipulate than that of other products.

- Field validation exercises found that mini track loaders can perform all ADR tasks, especially when multiple units are employed.

- Based on the field validation exercises, it was found that all of the Tenant sweepers performed about the same. The leanest, lightest performer in this category was the S 30 . 


\section{References}

Air Mobility Control Unit. 2014 (May). AMC affiliation workbook 36-101 Volume 2: Scott $A F B, I L H Q A M C / A 3 C M a i r l i f t$ planner course. Scott AFB, IL: Headquarters, AMC.

Bobcat. 2016. Bobcat Company Mini Track Loaders/MT85 Mini Track Loader. Bobcat: One tough animal. www.bobcat.com. (Accessed 15 March 2016).

Broce Manufacturing Company. 2015. The original self-propelled sweeper: Broce 350. Broce Broom. www.brocebroom.com. (Accessed 10 March 2016).

Caterpillar. 2016. New compact track and multi terrain loaders: 279D. CAT. www.cat.com/en_US/products/new/ equipment/compact-track-and-multi-terrain-loaders. (Accessed 20 February 2016).

Ditch Witch. 2016 Mini Skid Steers/SK750/SK350 Mini Skid Steer. Ditch Witch. www.ditchwitch.com/mini-skid-steer. (Accessed 15 March 2016).

Interim Tactics, Techniques, and Procedures (TTP). 2015. Revision 5. Airfield damage repair (ADR) interim process for recovery after attack. www.wbdg.org/ccb/AF/AFP/afpam10_219_v4.pdf(Accessed 10 April 2016).

Tennant Company. 2016. S30 mid-sized rider sweeper/ 800 industrial rider sweeper/Sentinel. Tennant. www.tennantco.com. (Accessed 10 March 2016).

Toro Company. 2016. Dingo TX 525 wide track. Toro. www.toro.com. (Accessed 10 March 2016). 


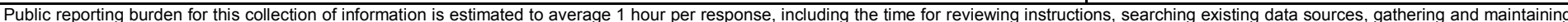

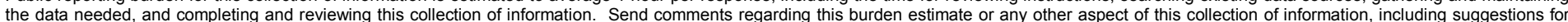

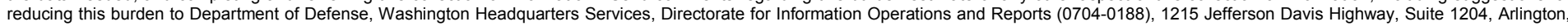

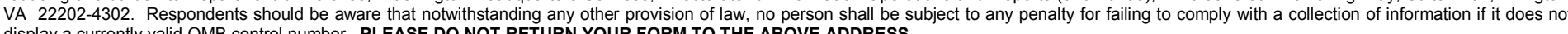
display a currently valid OMB control number. PLEASE DO NOT RETURN YOUR FORM TO THE ABOVE ADDRESS.

\begin{tabular}{l|l} 
1. REPORT DATE (DD-MM-YYYY) & $\begin{array}{c}\text { 2. REPORT TYP } \\
\text { Final report }\end{array}$ \\
\hline
\end{tabular}

\section{TITLE AND SUBTITLE}

Modernization of Deployable Airfield Debris Removal Equipment

\section{AUTHORS}

Ryan C. Strange, Jeb S. Tingle, Donald E. Yule, and Craig A. Rutland

3. DATES COVERED (From - To)

5a. CONTRACT NUMBER

5b. GRANT NUMBER

5c. PROGRAM ELEMENT NUMBER

5d. PROJECT NUMBER

457442

5e. TASK NUMBER

5f. WORK UNIT NUMBER

BFK2C4

\section{PERFORMING ORGANIZATION NAME(S) AND ADDRESS(ES)}

8. PERFORMING ORGANIZATION REPORT NUMBER

U.S. Army Engineer Research and Development Center

Geotechnical and Structures Laboratory

ERDC/GSL TR-17-2

3909 Halls Ferry Road

Vicksburg, MS 39180-6199

9. SPONSORING / MONITORING AGENCY NAME(S) AND ADDRESS(ES)

Headquarters, Air Force Civil Engineer Center

Tyndall Air Force Base, FL 32403-5319
10. SPONSOR/MONITOR'S ACRONYM(S)

11. SPONSOR/MONITOR'S REPORT NUMBER(S)

Approved for public release; distribution is unlimited.

\section{SUPPLEMENTARY NOTES}

\section{ABSTRACT}

Research was conducted at the U.S. Army Engineer Research and Development Center to evaluate leaner, lighter equipment for deployable debris removal post missile strikes for airfield damage repair (ADR). LiDAR scans were obtained prior to and after the initial debris removal and were also used in the final debris removal process when using vacuums and sweepers. Photogrammetry was used to obtain measurements and to calculate volumes. A market survey of available loading and sweeping equipment was conducted to populate a database of physical dimensions and time relationships according to identified ADR tasks. Selected equipment was evaluated for maneuverability and efficiency in a realistic environment. Results indicate that mini track loaders with a maximum rated weight of 3,000 $\mathrm{lb}$ are capable of performing all identified ADR tasks with an efficiency at or better than the currently utilized 10,000-lb track loaders. Results also indicate that sweeper vacuums with a maximum rated weight of 3,500 lb are capable of performing all identified ADR tasks with an efficiency at or better than the currently utilized 20,000-lb vacuum trucks.

\section{SUBJECT TERMS}

Runways (Aeronautics) - Maintenance and repair
United States - Armed Forces -

Equipment and Repair

\begin{tabular}{|l|l|l|}
\hline \multicolumn{2}{|l|}{ 16. SECURITY CLASSIFICATION OF: } \\
\hline a. REPORT & b. ABSTRACT & c. THIS PAGE \\
UNCLASSIFIED & UNCLASSIFIED & UNCLASSIFIED \\
\end{tabular}

17. LIMITATION OF ABSTRACT

\begin{tabular}{l|l|l|l} 
18. NUMBER & 1 \\
OF PAGES & \\
\cline { 2 - 2 } & 1 \\
& &
\end{tabular}

19a. NAME OF RESPONSIBLE PERSON

19b. TELEPHONE NUMBER (include area code) 